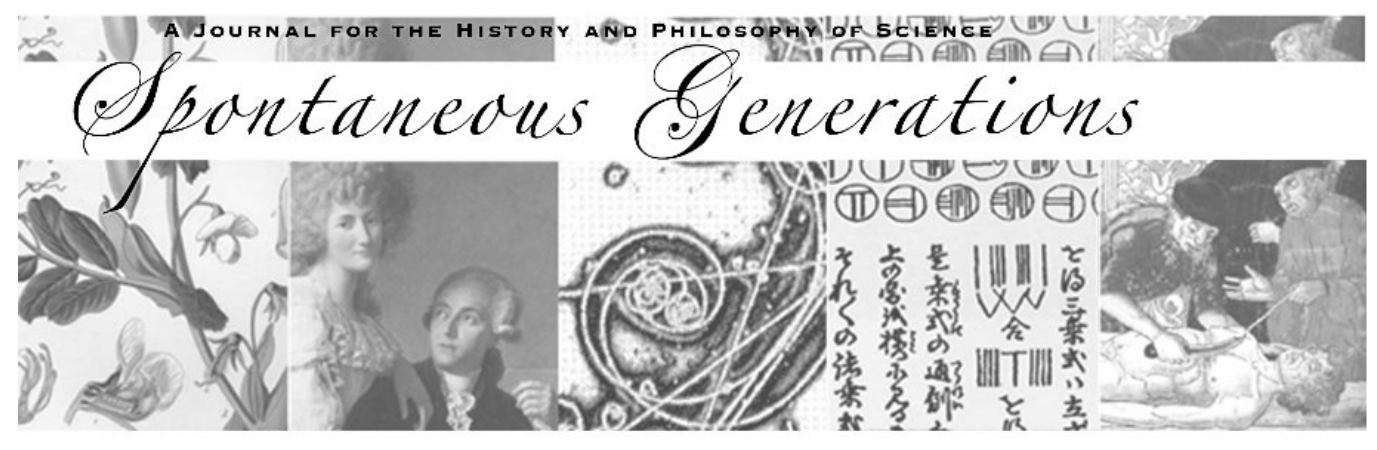

Instruments and Practices in the Development of Planetary Geology

Author(s): Matthew Shindell

Source: Spontaneous Generations: A Journal for the History and Philosophy of Science, Vol. 4, No. 1 (2010) 191-230.

Published by: The University of Toronto

DOI: $10.4245 /$ sponge.v4i1.11954

EDITORIAL OFFICES

Institute for the History and Philosophy of Science and Technology

Room 316 Victoria College, 91 Charles Street West

Toronto, Ontario, Canada M5S 1K7

hapsat.society@utoronto.ca

Published online at jps.library.utoronto.ca/index.php/SpontaneousGenerations ISSN 19130465

Founded in 2006, Spontaneous Generations is an online academic journal published by graduate students at the Institute for the History and Philosophy of Science and Technology, University of Toronto. There is no subscription or membership fee. Spontaneous Generations provides immediate open access to its content on the principle that making research freely available to the public supports a greater global exchange of knowledge. 


\title{
Peer-Reviewed
}

\section{Instruments and Practices in the Development of Planetary Geology ${ }^{*, \dagger}$}

\author{
Matthew Shindell ${ }^{\ddagger}$
}

\begin{abstract}
This paper examines the roles played by instruments and their associated practices in the development of the field of planetary geology. Specifically, remote sensing instruments and the images produced by instrument users are discussed. It is argued that through these instruments and images the first two generations of planetary geologists were able to "domesticate" the planets and make them suitable for geological study. But this was not a straightforward process. The instruments themselves had to be "domesticated" as geological tools, and the definition of "geologist" had to be broadened to include such tools and extraterrestrial terrains. This paper looks first at the first generation of planetary geologists associated with the mapping and study of the Moon in the 1960s and 70s, then focuses on the second generation that emerged during the exploration and mapping of Mars. Within this second section, the paper focuses on the introduction of one new type of instrument-the orbiting infrared spectrometer-and examines three such instruments and the visual claims made with its images.
\end{abstract}

* This paper is related to my master's thesis, "Outside the Revolution: Turning Points in Planetary Geology and the Introduction of Thermal Infrared Spectroscopy" (Arizona State University [ASU], 2004). I am indebted to ASU planetary geologist Philip Christensen for allowing me complete access to his time, facilities, and instrument team at the ASU Mars Space Flight Facility for two years, and for allowing me to shadow the Mini-TES team at JPL during the initial months of the MER mission. I am also indebted to my ASU advisors, Jane Maienschein and Manfred Laubichler, for overseeing the writing of the thesis. An earlier version of this paper, "Astrogeology in Translation: The Construction of Extraterrestrial Frontiers in the Early Years of Planetary Science," was presented at the 2007 History of Science Society meeting in Crystal City, Virginia. I thank my current advisor Naomi Oreskes and Steven Epstein for providing comments on the HSS paper. Also thanks to Erik Conway of NASA JPL for organizing the HSS Panel. My colleagues at the Chemical Heritage Foundation and the Philadelphia Area Center for the History of Science, Carin Berkowitz, Ronald Brashear, John Ceccatti, Hilary Domush, Anna Geltzer, Benjamin Gross, Roger Horowitz, Matteo Martelli, Evan Ragland, Annalisa Salonius, and James Voelkel, and also my UCSD colleagues Matthew Crawford, Mark Hineline, and Cynthia Schairer provided comments on later drafts of this paper.

$\dagger$ Received 27 February 2010. Revised paper accepted 21 June 2010.

$\ddagger$ Matthew Shindell is a PhD candidate in the History of Science and Science Studies, Department of History, University of California, San Diego. He is also a Haas Fellow at the Chemical Heritage Foundation. 
Prelude and Introduction: Robotic Geologists on Mars

In January 2004, the National Aeronautics and Space Administration (NASA) successfully landed two robotic Mars Exploration Rovers (MERs), named Spirit and Opportunity, on the surface of Mars. NASA scientists and public relations officers anthropomorphized the MERs in press conferences and in their descriptions of their own day-to-day interactions with the rovers. ${ }^{1}$ Press releases and fact sheets produced by NASA and the Jet Propulsion Laboratory (JPL) where the rovers were designed even announced that the rovers had a profession-they were field geologists-and described the geological nature of the MERs' work as follows:

First, a panoramic camera at human-eye height, and a miniature thermal emission spectrometer with infrared vision help scientists identify the most interesting rocks. ... The rover drives to the selected rock and extends an arm with tools on the end. Then, a microscopic imager, like a geologist's hand lens, gives a close-up view of the rock's texture. Two spectrometers identify the composition of the rock. The fourth tool substitutes for a geologist's hammer. It exposes the fresh interior of a rock by scraping away the weathered surface layer. (NASA JPL 2003)

Elsewhere, NASA described the rovers' Athena instrument package as "a geology toolkit" and likened the rovers' ability to scout out surroundings and move to scientifically interesting targets as being "like [that of] a human field geologist" (NASA JPL 2004). The reason given for sending these robotic geologists to Mars was straightforward: NASA was looking for clues to Mars' possibly watery past, and, in the words of MER principal investigator Steven Squyres, "the clues are in the rocks" (NASA JPL 2003).

The twin rovers came with twin assumptions: a rocky surface, no matter where it is found, is best explored by the methods of the field geologist, and a properly equipped robotic surrogate can stand in for a human geologist when conditions demand it. However, tracing the history of planetary geology reveals that a great deal of disciplinary work was necessary

1 The implications of this anthropomorphizing and of the social roles bestowed upon the rovers in interactions with their human users are not addressed in this paper, but are being explored by my UCSD colleague Cynthia Schairer. Janet Vertesi, a recent graduate of Cornell University's Department of Science and Technology Studies, is engaged in a very enlightening exploration of what she calls "the social life of spacecraft." Vertesi has also finished a PhD dissertation at Cornell, which is an ethnography of the MER mission (Vertesi 2009). 
before field geologists could properly lay claim to planetary surfaces other than Earth's and before the instruments onboard the rovers could be considered geological tools. Such an exploration provides a glimpse of what is involved when a new scientific discipline or subdiscipline sets out to study an unfamiliar object, and the role that instruments and the practices surrounding them play in that process. From a historical viewpoint, the construction of the MER rovers becomes more than the accomplishment of engineering a machine in the likeness of a human scientist; just as significantly, it becomes the accomplishment of a community of scientists who have carved out disciplinary as well as methodological territory-an accomplishment that was shaped by the political, economic, and social context within which it was achieved.

The first section of this paper addresses planetary geology's formative years during the 1960s, culminating in the Apollo lunar exploration program. This section will focus primarily on the work undertaken by astrogeologists from the United States Geological Survey (USGS), which sought to prove that the methods of field geology (translated primarily into photogeology) had a place in planetary science. This includes arguments within the discipline of geology over the appropriateness of taking the formerly Earth-bound science to extraterrestrial landscapes, as well as turf battles between geologists and scientists from other disciplines about whether or not field geologists had the expertise or training necessary to take part in space-age exploration. This section will also address the practices that the astrogeologists engaged in to make their own area of expertise-the field-vital to planetary exploration. Instruments and practices played key roles in negotiating the place of the field geologist in planetary science and in constructing an extraterrestrial field within which the geologist could work.

The second section of this paper, which is based largely on interviews conducted by the author with planetary geologist Philip Christensen, ${ }^{2}$ addresses the introduction of a specific type of instrument to planetary geology-the infrared (IR) spectrometer. The IR instruments described in this section evolved over the course of three separate Mars missions before they appeared, in miniaturized form, as the mini-Thermal Emission Spectrometer (mini-TES), onboard the MERs. The story of these spectrometers is provided not as the complete story of the MER instrument package, nor even as the complete story of IR martian geology, but as an illustration of the ways in which instruments and their users co-evolve. Instruments alone do not develop relationships with the objects

2 The interviews with Christensen and planetary geologist Ronald Greeley are available in more complete form in the author's 2004 dissertation (Shindell 2004). 
they are used to decipher. The mini-TES and its predecessors are geological instruments because Christensen and his team have, through the development of practices and user communities, embedded them within geological work. Likewise, Christensen's success with IR does not stem solely from the inherent properties of Mars and the corresponding design of his instruments, but from his translation of NASA's mission priorities, his utilization of existing resources and relationships within NASA and the space science community, his construction of a "center of calculation" for IR mineralogy, and his successful use of this centre for the training of a new generation of planetary geologists to carry out IR work. ${ }^{3}$

This examination of the co-development of users, instruments, and the practices that connect them reflects a commitment to a heterogeneous constructionist view of instruments. Within this view, the instrument is not a simple extension of the senses of the scientist, but one part of a social project of perception. In this understanding, the instrument and the practices surrounding it compose what Michael Lynch has described as an "externalized retina" that "[activates] the perceptible and schematically [processes] it" (Lynch 1985, 59; Lynch 1988). Instruments are thus intimately connected with the construction and "domestication" of the object of study, in that they, along with their users, produce visual representations that embody nonvisual information such as theoretical assumptions, laboratory analysis, methods of quantification, etc. In the case of planetary geology, this domestication takes the form of the production of geological maps of the lunar and martian surfaces.

\section{Taking Field Geology from the Colorado Plateau to the MOON}

The Cold War Origins of Astrogeology: Examining a Counter-Trend

Writing in 1982 about geology's "second flowering" after World War II, geologist Preston Cloud described the postwar advancements that had "brought the study of the Earth back into the main stream of advancing science and linked it with the sun and planets" (Cloud 1982, 34). By Cloud's account, these advancements included plate tectonics, geochronology by isotopic methods, and the birth-thanks to the space program-of comparative planetology. Concluding his own rough sketch of these advancements, Cloud argued

that geology since mid-century has changed significantly from the geology of the past. It has become a more dynamic, more

3 The term "center of calculation" is borrowed from Bruno Latour (1987). 
quantitative, more inclusive, more theoretically oriented, and more unified subject than it was. It has been enriched and diversified by an influx of faculty and students from physics, chemistry, and biology. It has expanded to include not only the traditional continental surfaces but the once remote floor of the sea, the once impenetrably deep structure of the planet, the once unbelievably long whole evolution of the Earth and its biotas leading to us, and an ever-broader utilization of geochemical and mineralogical indicators of paleotemperature, paleopressure, paleosalinity and other paleoenvironmental variables. It has also become clear that the principles and practices of geology, including geochemistry and geophysics, apply with equal force to other planets, leading us routinely to employ such semantically jarring terms as the geology of Mars, lunar earthquakes, and even astrogeology. In short, geology has broken its traditional bounds to become a universal science-a body of principles, methods, and evidence that embraces meteoritics, comparative planetology, and even pre-solar history, as well as planet Earth itself. (Cloud 1982, 47-48)

Largely, the story Cloud tells here has been borne out by historical studies of the earth and planetary sciences since World War II. In her study of plate tectonics, Naomi Oreskes determined that after the war, geologists did indeed change their methodological preferences, shifting away from a prewar American style of inductive argument from field observations to new instrumental methodologies and evidence imported from physics and geophysics (Oreskes 1999). The work of Stephen Brush and Ronald Doel has likewise shown how the postwar migration of physicists and physical chemists to the earth sciences led to the importation of such instruments as the mass spectrometer, giving rise to new isotopic methods of dating geologic materials and determining paleoclimate as well as new research programs in meteoritics, cosmogony, and elemental abundances that drew the attention of these geochemists and geophysicists to meteorites and to the planets (Brush 1996a; Brush 1996b; Doel 1996). In terms of the integration of the biological sciences into the earth and planetary sciences, Steven Dick and James Strick's work on NASA's exobiology and astrobiology programs has shown how the Space Administration helped to provide an institutional framework within which work on the origin of life and life's effects on its nonliving environment could be organized (Dick and Strick 2004). As these works and others have demonstrated, this shift was greatly encouraged by the emergence of new patrons during the Cold War, such as the Atomic Energy Commission (AEC) and the 
Office of Naval Research (ONR), and later NASA, who, with the looming threat of global warfare, had no small stake in the expansion of the earth and planetary sciences (Conway 2008; Dennis 2003; DeVorkin 1992; Doel 2003; Oreskes 2003). ${ }^{4}$

The existing narrative convincingly emphasizes the movement away from qualitative, observational, descriptive, and inductive methods in the earth sciences during the Cold War. If the universal science Cloud described did indeed emerge, it would seem to have been the product of the marriage of physical methods and military/space technologies with geological and astronomical questions. One aspect of this story that has not yet been adequately addressed is the movement of field geologists, and of field methods, to the study of extraterrestrial planetary surfaces. While participant histories have been written, and provide an insider's view of the field geologists' experience during the early years of planetary exploration (Wilhelms 1993; Beattie 2001; Schaber 2005), historians have not yet incorporated these histories into the narrative of postwar earth and planetary science. The case of the field geologists who became involved in lunar and planetary work in fact runs nearly counter to the trend described above. One must of course take Donald Wilhelm's participant account with a grain of salt when he claims, for example, that the success of these geologists in making the Moon "a world of rock" marked the dethroning of "the physicists and other quantitatively minded scientists who once dominated space science" (Wilhelms 1993, x). Clearly, field methods were transformed by their encounter with NASA and space science. However, a study of the field geologists within the USGS who took up the study of the planets (and who labeled themselves astrogeologists) does show that some of the same Cold War patrons and pressures kept field work alive even as the geosciences as a whole moved away from the field and formed strong prejudices against observational methods. These same forces allowed field geology to carve out a prominent place for itself within the newly forming planetary science community-a place from which it was able to reinvent its methodologies via new remote sensing technologies.

Although the USGS did not receive patronage expressly for planetary work until 1960, USGS field work, as well as many of the field geologists who later became involved in planetary work, was nonetheless an early recipient of Cold War patronage. From the immediate postwar years up until 1958, the USGS received an unprecedented level of patronage from

${ }^{4}$ Carsten Reinhardt and Nicolas Rasmussen have told similar stories about the incorporation of physical instruments in chemistry and biology during the Cold War (Reinhardt 2006; Rasmussen 1997). Angela Creager's new work describes the application of isotope tracers in biology and ecology, as well as the steps the AEC took to promote their use (Creager 2006). 
the newly established Atomic Energy Commission. The amount of funding the USGS received during these years reflected the AEC's anxiety over replenishing American uranium stores, which were depleted during the war. ${ }^{5}$ In order to secure sufficient uranium to continue the production of nuclear weapons and to develop a peacetime program of nuclear energy, the AEC's Division of Raw Materials sponsored several USGS activities in the Colorado Plateau. These activities, which were intended to stimulate a uranium mining industry, involved geological mapping in known uranium-bearing regions, stratigraphical studies of known ore-bearing formations, mineralogical studies of known ore deposits, studies in the geochemistry of uranium, and diamond-drilling campaigns to develop the known ore bodies. As a consequence of the Colorado Plateau project, the Geologic Division of the USGS grew rapidly (Shoemaker AIP Oral History Interview, June 16, 1987; Wilhelms 1993, 38). According to one participant, up to half of the Survey's funds during this period came from the AEC (Masursky AIP Oral History Interview, June 18, 1987). When AEC patronage of the Survey was suddenly terminated in 1958, the USGS scrambled to find new sources of funding for its geologists.

The withdrawal of AEC funding highlighted the Survey's growing dependence on external funding. It also made the Survey's then-director, Charles Anderson, wary of letting the USGS repeat this mistake with another new funding agency. This attitude made it unlikely that Anderson would act on a proposal, submitted by Eugene Shoemaker in 1958, to solicit money from the newly formed NASA to fund a photogeological study of the Moon. Anderson was, however, willing to allow the well-equipped and well-staffed but severely under-funded labs of the Survey's Geochemistry and Petrology Branch (also formerly supported by AEC money) support themselves by collaborating on a service level with NASA (Wilhelms 1993, 43). Shoemaker, though discouraged, remained persistent in his conviction that field geology should have a place in lunar exploration.

Shoemaker, who had worked on the Colorado Plateau project, had also studied craters at the Nevada Test Site in 1956 as part of another AEC funded program, the Megaton Ice-Contained Explosion (MICE) project, related to the AEC's interest in plutonium. ${ }^{6}$ Shoemaker's study of the

5 This same anxiety would help Harrison Brown and Lee DuBridge to receive generous AEC funding for a superbly equipped geochemistry lab when Brown moved to Caltech in 1952 ("Proposal for Research Project, Study of the Fundamental Geochemistry of Critical Materials and the Development of Economic Processes for Their Isolation," Box 14, CDGPS).

${ }^{6}$ MICE was a study initiated by the AEC to explore alternative means of producing plutonium. When the Hanford facility initially failed to produce plutonium on schedule, 
nuclear craters did not, in the end, help the AEC to produce plutonium. The craters did, however, give Shoemaker a new understanding of the processes involved in crater formation, which he was then able to apply to describing the origins of what is now known as Meteor Crater in Arizona. While working on the Meteor Crater problem, Shoemaker teamed up with USGS geochemist Edward Ching-Te Chao, of the Geochemistry and Petrology Branch. Shoemaker and Chao reported the discovery of the first known natural occurrence of coesite, a polymorph of silicon dioxide that they proposed to be an indicator of high-pressure, high-temperature "shock" events such as meteor impact (Chao, Shoemaker, and Madsden 1960). This work caught the attention of William Pecora, who was Chao's Branch Chief at the time; Pecora saw this discovery as confirmation that the USGS had the necessary expertise to combine observational field work with laboratory methods and become a participant in lunar exploration. Pecora arranged a press release for the publication, ensuring that the finding would also be noticed by NASA (Wilhelms 1993, 44-45). In August 1960, the USGS Astrogeology Branch began its existence with US $\$ 200,000$ of NASA funding. All told, NASA would provide $\$ 30$ million to the USGS from 1961 onward for its lunar work (Beattie 2000, 72).

\section{Constructing a Field with Telescopes and Cameras}

Much of what we know about the Moon comes through the use of remote sensors. For the most part this phrase is a vaguely impressive synonym for the words "telescope" and "camera"...

Thomas Mutch, Geology of the Moon, 1970.

Although it did incorporate geochemistry, the Astrogeology Branch had a strong field component. Many of the branch's founding members, including Shoemaker, had studied geochemistry and had experience with physical instruments, but their primary training and experience in geology had been in the field. They tended to favour "eyeball" observations of spatial relationships and morphology over quantitative data. One of Shoemaker's earliest recruits, Harold Masursky, who attended Yale on the Gl Bill after the war, had done much of his $\mathrm{PhD}$ dissertation research on horseback, constructing geological maps. While Yale's geology department would later be transformed by geochemists and theoretical petrologists, field work still dominated during Masursky's time

the AEC perceived a crisis in production. MICE proposed wrapping a nuclear device in a blanket of uranium, exploding the device underground (or in ice), then retrieving the plutonium produced during the explosion from the surrounding material (Shoemaker AIP Oral History Interview, June 16, 1987; Levy 2000, 73-75; Doel 1996, 177). 
there (Masursky AIP Oral History Interview, June 18, 1987). Another early recruit, Michael Carr, had attended Yale just after Masursky. Although Carr got a background in geochemistry and learned to use spectrometers, Yale had not yet fully transitioned and its faculty still promoted the field as the primary site of geological study. Likewise, even though Wilhelms reports that field work was beginning to be viewed with skepticism when he proposed a field dissertation at UCLA in 1958, Wilhelms found himself in a geology department that still looked favorably upon such work (Wilhelms AIP Oral History Interview, June 22, 1987). ${ }^{7}$

Shoemaker and his colleagues could not do field work directly on the Moon. Nonetheless, they attempted to produce the types of geological maps that a field geologist would construct from field observations. The first instruments used by the astrogeologists in this work were ground-based telescopes and cameras. In their previous work, many of the astrogeologists had learned techniques of photogeology, and they had become accustomed to making maps from aerial photographs. Shoemaker and Masursky both had experience with photogeological methods in the uranium project. Masursky, who attended Engineer Officer Candidate School during the war, had the additional experience of being attached to an engineering topographic battalion; here he had learned photogrammetry with projection plotters, and had used the technique to map the Northern Burma Campaign (Masursky AIP Oral History Interview, June 18, 1987). When a November 1960 announcement in Science Magazine introduced the Survey's new Astrogeology Branch, photogeology was chief among its activities (News Notes 1960, 1302).

One of Shoemaker's first projects was to use a photo purchased from the California Institute of Technology (Caltech) bookstore to produce the first modern stratigraphical study of lunar features (Shoemaker and Hackman 1962) (see Figure 1, below). David Levy, his future collaborator in the discovery of the comet Shoemaker-Levy, described this work as follows:

Gene proceeded with his lunar field work in much the same way he had out on the Colorado plateau. He couldn't do the field work himself-not yet, at least-with hands, feet, geologist's hammer, compass, and pacer, but he could vicariously with his eyes. Some forty years earlier, on exceptionally steady nights when the 100-inch Hooker telescope at California's Mt. Wilson Observatory was new, Francis G. Pease had taken such high quality photographs of the Moon that they

7 Pettijohn (1984) discusses this type of institutional transformation at the University of Chicago. Oreskes (1999) discusses this trend in postwar America more generally. 
picked up craters as small as one kilometer in diameter. Shoemaker had enlargements made of the region around the crater Copernicus, a hundred-kilometer-wide feature that he thought resulted from an ancient comet impact. From these photographs his team made the first geologic map of a lunar feature. (Levy 2000, 85)

This type of work was also carried out by the entire astrogeology team, whose members took turns observing quadrants of the Moon using the Lick Observatory's 36-inch refractor and the Lowell Observatory's Clark refractor. The derivation of stratigraphical maps from photographs and remote imagery was further reinforced when NASA built the astrogeologists their own observatory, staffed by USGS personnel and used exclusively for lunar mapping. The trend continued with the lunar images returned by the robotic Lunar Orbiter, Ranger, and Surveyor missions, all of which carried cameras and delivered thousands of black and white images via television signal. ${ }^{8}$

The USGS geologists were not the only geologists receiving funding for lunar mapping, nor were they the only ones learning to work with remote camera imagery. NASA was also drawing from other existing federal stores of geologists and putting them to work mapping the lunar surface. Ronald Greeley, for example, a freshly-minted geology PhD with a Reserve Officers' Training Corps commitment, was first assigned to the U.S. Army's Intelligence unit, where he went through image interpretation school. With this training, the army intended for Greeley to interpret aerial photos in studies for a new Panama Canal. ${ }^{9}$ At NASA's request, however, Greeley spent his military career in a civilian capacity at NASA's Ames Research Center, where NASA had established its own Planetology Branch: "NASA had number one priority for manpower throughout the federal government, including the military, and geology was a critical skill at that time" (Greeley 2003, October 9). The research interests of Greeley's supervisor at Ames, Don Gault, also intersected with those of the astrogeologists. Gault had constructed a laboratory facility at Ames in which he could create artificial impact craters. The facility, still in use today, provided, on top of Shoemaker and Chao's discoveries, a great deal of

8 The photos were actually developed and scanned onboard the spacecraft, then returned to Earth via video signal where the images were regenerated and transferred to $35 \mathrm{~mm}$ film. As one might imagine, this technique did produce a number of artifacts in the returned images.

9 During the 1960s there was some interest in either expanding or replacing the Panama Canal. The physicist Edward Teller even proposed using nuclear explosions to excavate a new waterway (Kirsch and Mitchell 1998). 
the basic understanding of the mechanics of impact cratering. Here Gault developed the vertical gas gun-a gun capable of firing straight down, or at 15-degree angular increments, into a vacuum chamber 8 feet in diameter and equally as tall. The gun used hydrogen to accelerate the projectile to the speed of 7 kilometers per second-seven times the speed of a high-speed rifle bullet, but still on the low end of impact velocities in the solar system, which were thought to range from 5 to 50 kilometers per second. Gault had a keen interest in both geology and impact cratering. $\mathrm{He}$ surrounded himself with geologists and developed an approach at Ames that combined geological understanding, engineering know-how, and physical experimentation (Greeley 2003, October 9). Gault's work intersected well with Shoemaker's interest in shock wave geology, and the astrogeologists provided Gault with the geological understanding he valued; Gault's team members became regular collaborators with the astrogeologists. Meanwhile the astrogeologists undertook terrestrial impact studies of their own at the White Sands Missile Range, where they could examine craters produced by missiles with known speeds and trajectories (Masursky AIP Oral History Interview, June 19, 1987).

\section{Early Objections: An Obscure and III-Defined Branch of Geology}

Not everyone was happy with the astrogeologists' initial success. In its early years, the Astrogeology Branch was considered within the USGS to be a temporary institution, and its activities were viewed with some skepticism. However, these internal tensions were rarely aired publicly, unlike the criticism astrogeologists received from their counterparts in geochemistry. ${ }^{10}$ Founded in 1960, the Astrogeology Branch was a relative latecomer to the nascent planetary science community. Planetary science began to take on disciplinary trappings in the mid-1950s, as the result of sponsorship by the National Science Foundation (NSF) and the emerging space program, as well as the heightened activity associated with the International Geophysical Year (1957-1958) and the launch of Sputnik.

${ }^{10}$ The AIP oral histories testify to a prejudice against field geology within the planetary science community. Shoemaker reports that most of his colleagues within the USGS treated astrogeology as a joke (Shoemaker AIP Oral History Interview, June 17, 1987), and that most of the scientists involved in lunar exploration had little understanding of (let alone appreciation for) field science (Shoemaker AIP Oral History Interview, September 8, 1988). Masursky indicates that these prejudices were tied to turf battles within mission planning, pointing out that most of the scientists involved in lunar exploration were more interested in isolating problems, designing experiments, and collecting samples for laboratory investigation than in exploring the surface (Masursky AIP Oral History Interview, September 8, 1988). Wilhelms recalls that geochemists and astronomers alike were skeptical that geologists could learn anything of scientific import by looking at pictures of the Moon (Wilhelms AIP Oral History Interview, June 22, 1987). 


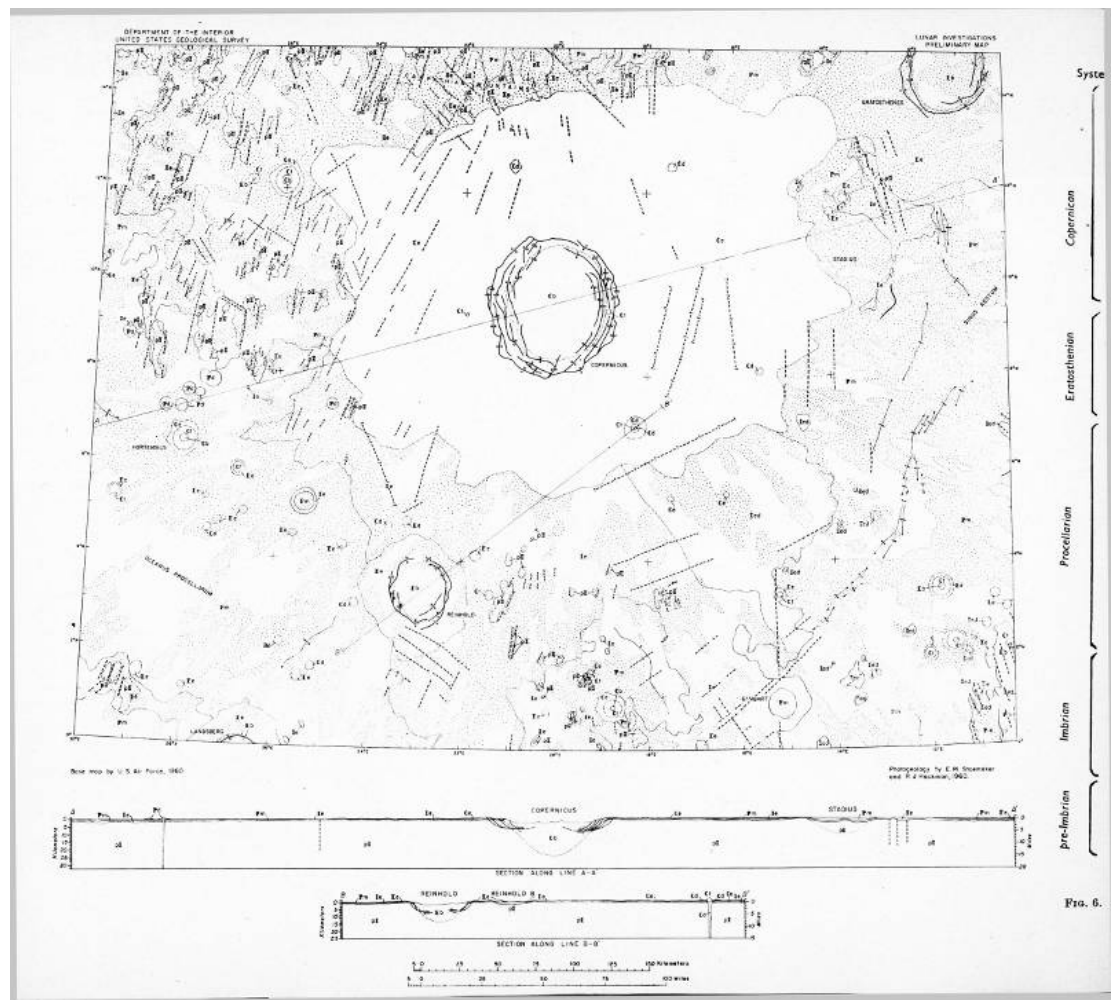

Figure 1. Shoemaker's map of the Copernicus region of the Moon. From Shoemaker, Eugene, and Robert Hackman. 1962. Stratigraphic Basis for a Lunar Time Scale. In The Moon, ed. Z. Kopal and Z. K. Mikhailov. IAU Symposium 14. New York: Academic Press. 289-300. Image reproduced with permission from the International Astronomical Union.

However, government and military patrons had already begun stimulating separate arenas of earth and planetary research immediately after the war. By the late 1940s this patronage had facilitated some very fruitful (though equally tense) collaborations between isotope geochemists and astronomers. By Doel's estimation, the influence these geochemists-chief among them Nobel Prize-winning physical chemist Harold C. Urey and his colleague at the University of Chicago Institute for Nuclear Studies, Harrison Brown-had on postwar solar system astronomy was unmatched (Doel 1996, 78). By the time the astrogeologists arrived on the planetary scene, attention was already somewhat focused upon certain disciplines and approaches, and the community was dominated by a handful of big personalities.

Urey had reinvented himself as an isotope geochemist after the war (while still maintaining the prestige of a nuclear chemist and a Manhattan Project alumnus) and had pioneered work on paleoclimate and elemental abundances; by the time NASA was formed he was eager to 
participate in what he insisted should be called "selenology" (as opposed to astrogeology or planetary geology). By moving into the geosciences, Urey and his peers had won accolades for their application of quantitative methods to a formerly qualitative field (Doel 1996, 78), and along with this came a prejudice against a return to qualitative work. ${ }^{11}$ Well into the 1960 s, Urey would clash continuously with the astrogeologists, claiming that they were "second rate" scientists who knew little basic science and had few publications to their names. In 1961, for example, Urey wrote in a letter to Al Hibbs at JPL:

I believe that geology is the worst training that can be given to a man for the investigation of the Moon and planets. The reason for it is this. Geology ... is largely a purely descriptive science with a very minimum training in the more mathematical aspects of chemistry and physics. It largely deals with description of rocks, sedimentary and igneous, and the gross features of the earth. I have been associated with geologists now for some 10 years and I have met a few who are good exact scientists, but the training which students get in the usual geology department is a very descriptive training. (Urey to A. Hibbs, September 26, 1961, Box 43, Folder 3, HCU)

Urey explained that the processes and theories geologists were familiar with would be of no use on the Moon, which he felt had a very different past than the Earth, and thus they would be blinded by their preconceptions and their allegiance to such theories as uniformitarianism. Urey then revealed his Manhattan Project biases as he went on to suggest that space scientists should be chosen from those disciplines that attracted the best and brightest scientific minds:

During the last fifteen years the brightest young men to come through our graduate schools are nuclear physicists. This has been the attractive field. Next to that are solid state physicists, and somewhere along here are physical chemists. ... What is needed in this field is to try to divorce one of these bright individuals from his chosen field, which is just damn crowded, and try to induce him to take an interest in another field. (Urey to A. Hibbs, September 26, 1961, Box 43, Folder 3, HCU)

\footnotetext{
${ }^{11}$ The qualitative-quantitative distinction is no doubt fraught with problems. Mapping and stratigraphy-both tasks that were deemed qualitative by their critics-clearly involve both observation and quantification. However, in the eyes of their critics in the "hard" sciences, the field geologists were practicing an outmoded and descriptive science that involved quantification on only the most basic level.
} 
It was not clear to Urey, whose strengths were concentrated in laboratory expertise, and who labeled the methods of field geology as inductive and antiquated, whether field geology had any place on the Moon. ${ }^{12}$

Urey was not alone in his opposition to the astrogeologists. While Urey based his arguments on an unfavourable comparison of geology with physics, others objected for reasons that, at least superficially, seem semantic. In the Bulletin of the Geological Society of America, geochemist Kalervo Rankama objected to "such obscure and ill-defined branches of geology as Astrogeology and planetary geology," arguing that the endeavor would be better described as planetology. Geology, Rankama argued, "is conventionally defined as the 'science of the Earth,' or 'Earth science,' with numerous branches. Clearly, geology is restricted to the study of the Earth and of terrestrial phenomena and does not apply to extraterrestrial bodies and processes." Rankama quipped, "With the establishment of the first bases on the Moon and on Mars, the first selenologists and planetologists are likely to join the ranks of geologists" (Rankama 1962). Rankama's objections were met in a 1965 issue of GeoTimes by astrogeologist Luciano Ronca. Ronca's argument for including the study of the Moon and planets under the heading of geology was made largely on methodological grounds: "Rankama has written that the term geology should be restricted to the study of the Earth, and selenology to the study of the Moon, and planetology for the study of the planets ... People studying the surface features of the Moon and planets are applying geological-not planetological-principles to what they see. The laws of superposition, sedimentation, erosion, and all other concepts that will be used in studying any planet are geological concepts" (Ronca 1965).

Ronca also felt compelled to meet Rankama on etymological grounds for the use of the prefix geo. Citing two different Greek-English dictionaries to make his case, Ronca argued that the prefix was historically used, and properly so, in ways translatable not only to the Earth, but also to the words "land, soil, ground, field, empire, home." Still, Ronca had to extend these meanings to the Moon and planets, something the Greeks had not done. To do this, Ronca, who found the common denominator of all of these terms to be their solidity and the ability to safely land, laid out his case as follows:

${ }^{12}$ Urey, at least in the beginning of his involvement with NASA, would have preferred robotic missions to the Moon that were sent to collect samples and spectral data. The terrain and features of the Moon were secondary to his interest in the composition of the lunar surface. 
The ancients traveled from land to land through the seas; astronauts will travel from planet to planet through space, and geo will have the same meaning in both cases. Geology will be the study of the place where they land. Thus geology may be intended to mean the study of any celestial body that is solid (thus excluding stars) and has also enough gravity to permit walking (thus excluding meteorites). Therefore I believe it is perfectly acceptable for even a purist to use the term geology of the Moon and planets without apologetic quotation marks (Ronca 1965).

Making such an extension made perfect sense to Ronca, who drew a direct parallel between humanity's seafaring past and its spacefaring future. Getting past Rankama's objection that without setting foot on the terrain one could hardly "join the ranks of geologists" required one further extension. Having already assumed the availability of the other planets for study, and that astronauts would travel from planet to planet, Ronca again enlisted the future: "Other planets will be soon available for direct exploration, and I hope they will be explored by geologists rather than planetologists" (Ronca 1965). That what was then being done remotely could potentially be done on foot was all the justification Ronca found necessary for applying the geo prefix to any planetary surface.

Brown University stratigrapher Thomas Mutch, one of the few geologists outside of the USGS to take up astrogeology, drew similar conclusions to Ronca's in his first textbook of planetary geology (Mutch 1970). ${ }^{13}$ Here he described the history of terrestrial geology as the exciting story of how fundamental questions had been answered through the slow and persistent study of the Earth. ${ }^{14}$ That the same type of work could now be done on the Moon, which might even uncover a stratigraphy comparable to that found on Earth, ${ }^{15}$ meant that fundamental questions could be asked once again. The Moon was, potentially, an extension of terrestrial terrain. It could thus be studied as such. It is in this context that Mutch introduced photogeology as the successor to traditional field work. In the absence of ground truth, Mutch advocated the use of Earth analogues in the stratigraphic interpretation of telescopic and spacecraft images, allowing astrogeologists to bring terrestrial field experience to bear on lunar surface

\footnotetext{
${ }^{13}$ Mutch's text was written after spending a sabbatical at the USGS Astrogeology Branch, and was completed with the assistance of the USGS astrogeologists.

${ }^{14}$ In Mutch's version of the history of geology, the discovery of plate tectonics was not a revolution, but part of this same steady advance of knowledge.

${ }^{15}$ Shoemaker's 1962 paper had suggested as much.
} 
features. ${ }^{16}$ For his frontispiece, Mutch chose an Ansel Adams' photograph, "Autumn Moon, High Sierra from Glacier Point"; portraying the Moon as it might be viewed by a field geologist on a clear night, the photo highlighted one of the book's main themes-the Moon was unexplored territory, but it was connected to something familiar and mapped.

Even though these battles with the experimental lunar scientists were a burden for the astrogeologists, there were some upsides to being part of this contentious community. While the astrogeologists did have to defend themselves against their critics within the lunar exploration program, they were to a large extent institutionally insulated from the prejudice against qualitative methods then gaining ground in American geology. Although Mutch described the progress of geology as continuous, much of the geological community was ready to hail plate tectonics as a revolutionary break from the past, and to "shift permanently the center of attention and significance away from stratigraphy and structural geology of continental rocks toward a geophysical study of ocean floors and the Earth's interior" (Greene 1985, 98). Greeley explains the following:

Right from the outset, producing geological maps of the Moon was an important part of the planetary program ... We did not feel [the prejudice against our work], in part because we were, at least to some degree, isolated from the geological community. We had a job to do, and that was to get to the Moon, and to do as much science as we could with the Moon, and the science was driven by and large by geology. So those of us who were involved with the program at the time took the conventional geological perspective that what you do when you go to any new place is make a map of it. (Greeley 2004, April 1)

Free from the obligation of having to justify themselves, the astrogeologists and planetary geologists developed methods of translating field experience into instrument use and image interpretation, and carried out their descriptive study of the Moon. They provided the images and maps used in Mutch's 1970 text and later atlases of lunar and planetary surfaces.

\section{Mobilizing the Field}

The real ground truth for this first generation of planetary geologists, and the first demonstration that field geology could in fact be practiced

${ }^{16}$ According to Wilhelms, although Mutch's arguments about photogeology were based on the work being done at the USGS, the introduction of terrestrial analogues (other than impact craters) was Mutch's unique contribution to planetary geology (Wilhelms AIP Oral History Interview, June 22, 1987). 
on an extraterrestrial surface, came during the Apollo manned lunar program. That NASA chose to have the astronauts train in field geology on Earth then conduct field geology on the Moon was itself the result of the successful translation of NASA's priorities by the astrogeologists and other geologists working within NASA's administrative corridors. Senior management had little to no training in the earth sciences. To sell the value of a geological approach to the Moon, the geologists mobilized the field. According to Donald Beattie, who was himself a geologist and the program manager for Apollo Lunar Surface Experiments, "We decided the best way to convince our bosses that there would be exciting and important investigations for the astronauts to undertake on the Moon (requiring many days and a wide variety of equipment) would be to illustrate these tasks with terrestrial analogies and describe the type of field work and experiments required on Earth to unravel its own history." They developed "a short course on terrestrial geology and geophysics for NASA decision makers-and extrapolated this lesson to the Moon" (Beatie 2001, 31). Images of the Earth and Moon and discussions of terrestrial field geology became parts of the promotion of scientific activity to NASA higher-ups.

Beatty and his geologist colleagues were able to convince NASA that geological field work would "optimize those aspects of exploration that humans do best: observing, describing, manipulating complex equipment, and responding to the unexpected" (Beatty 2001, 41). This was essential to making their case, as Apollo's managers were trying to strike a delicate balance between automated functions that minimized human error and manual tasks that took advantage of the astronauts' human abilities. Shoemaker, who had by then successfully cultivated relationships with NASA mission planners, and had served as principal investigator on the Surveyor TV Camera experiment, was called to Washington to help plan management of Apollo's scientific program in 1962. From this position, Shoemaker argued that the astronauts should be trained in field geology so that they would be able to identify valuable rock samples and make decisions in situ that could not be made ahead of time or remotely (Shoemaker AIP Oral History Interview, September 8, 1988). Despite vocal opposition from their nongeologist colleagues, Shoemaker and his colleagues did succeed in having a strong hand in training the astronauts. According to Masursky, this success was not only testament to Shoemaker's growing reputation within NASA, but also to the rapport the geologists developed with the astronauts and the mission controllers (Masursky AIP Oral History Interview, September 8, 1988). Even Urey, who thought so little of field geology, eventually became convinced that without giving the astronauts something to do on the Moon, the appearance would be generated that Apollo was accomplishing nothing 
scientific that could not be done with robotic orbiters and landers: "The Apollo project is being severely criticized by outstanding people, and I believe that if we do not at least [do] the very best that we can to solve important scientific problems [with the astronauts] that this criticism may well swell to a very great chorus." He recommended that "all astronauts be well trained hard rock geologists."17 NASA ultimately agreed, and a field geology team led by Shoemaker trained the astronauts in the methods and language of field geology, and even saw them through many of their simulated Moon landings.

After the astronauts put these geological lessons into practice on the Moon, and provided some ground truth to the claims of the photogeologists working back on Earth, a precedent for field work on extraterrestrial surfaces was established. In the years that followed Apollo, with the initial stakes of mission planning largely removed, and with no theory of the Moon's origin emerging victorious, lunar science did see a new synthesis of field and laboratory methods and an end to some of the disciplinary tensions that had plagued its earlier years. Apollo's premature termination in 1972 left no foreseeable means of continuing direct scientific exploration of the Moon. Lunar researchers made the most of existing photogeological studies of lunar landforms and their relative ages, fitting them with isotopic studies of the age and geochemistry of returned lunar rock and soil samples, and extending their lunar observations to arguments about the development of silicate planets in general (Lowman 1972; Lowman 1976). This entry into comparative planetology was aided, of course, by the ongoing robotic exploration of another rocky planet-Mars. The astrogeologists were now participating in a discipline that found value in laboratory and field work, and which could properly be called planetary geology without much further debate. ${ }^{18}$

\section{EXPANDING TERRITORY AND INTRODUCING NEW INSTRUMENTS}

Part 1 of this paper discussed the conditions that allowed field geology to flourish within NASA's lunar exploration program, even as growing prejudices among planetary scientists and academic geologists diminished the perceived value of field work in the geosciences. It also

\footnotetext{
${ }^{17}$ Urey to J. Holmes, January 10, 1964, HCUN.
}

${ }^{18}$ Also around this same time, the first Earth Resources Technology Satellite (ERTS 1), later to be named Landsat, was put into orbit. The development and launch of this satellite reflected an ongoing collaboration between NASA and the USGS (as well as other parts of the Department of the Interior), indicating that the USGS no longer viewed NASA patronage with the same skepticism it had in the late 1950s. The astrogeologists were no longer outliers within the USGS because of their use of remote sensing, but leaders. 
showed how, by the end of Apollo, the new discipline of planetary geology incorporated field methods and an understanding of geology in the form of photogeology and its associated practices, and combined it with more quantitative approaches developed by geophysicists and geochemists. Part 1 demonstrated that the first assumption behind the MER rovers-rocky surfaces, no matter where they are found, are the terrain of the field geologist-is not a natural assumption but rather the result of a rich and at times unlikely history involving Cold War patronage, institutional growing pains, bureaucratic maneuverings, and the translation of new instrumentation (much of it with military origins) to geological purposes.

Part 2, which moves from lunar to martian terrain, addresses the second assumption behind the MER rovers-a properly equipped robotic surrogate can stand in for a human geologist when conditions demand it. While this section picks up the narrative of planetary geology at roughly the point at which Part 1 ended, it is not intended to be a linear continuation of the story told up to this point. Although some of the history of martian exploration post-Apollo is provided in order to illustrate some of the changes occurring within planetary geology during this period, this section is not an attempt at a comprehensive history of martian exploration. Rather, Part 2 is an examination of the origins and development of the series of IR instruments that led to the mini-TES instrument onboard the MER. It is meant to illustrate how geological practices and communities form around instruments, develop in parallel with instruments in significant and interesting ways, and participate with instruments in making geological images of the planets. These activities effectively amount to the maintenance of a subdiscipline of IR mineralogy within the Mars community, and constitute the social project of perception of Mars in the IR within which the instruments are domesticated. Because of the choice to focus this section of the paper on one sequence of instruments and on one principal investigator, the story takes the form of a linear narrative. This appearance is reinforced by the mission-based nature of NASA's Mars exploration program and the momentum of mission-to-mission instrument development. However, the themes highlighted here are very much in line with the constructionist view outlined in the introduction. Philip Christensen's success with IR stems not solely from the inherent properties of Mars and his ability to decipher them, but from his translation of NASA's mission priorities, his utilization of existing resources and relationships, his construction of a "center of calculation" for infrared mineralogy, and his successful use of this centre for the training of a new generation of planetary geologists to carry out IR work. 


\section{Mars is Not the Moon}

The first boon for Mars geology was the 1971 Mariner 9 mission. This was the first orbiting robotic mission to Mars, and the first to collect global datasets. The 7239 images of the martian surface recorded by the spacecraft then transmitted back to Earth formed the basis for the first modern geological map of Mars. Mariner 9 provided a turning point for planetary geology. It signified more than just a move away from lunar geology. The new view of Mars provided by Mariner 9 allowed geologists to construct a frontier, neither lunar nor terrestrial, of new and exciting territory filled with grand geologic features, which they could explore through photogeological interpretation (Sheehan 1986). The visual data gathered during the Mariner 9 mission were accompanied by an increased rate of new discovery, along with what was deemed a striking "obsolescence of old ideas" in planetary science. Mutch, who used the dataset and the maps from which they were produced to write a second textbook on photogeological stratigraphical methods, described the transformation of Mars during the mission as follows:

To a geologist, each day's pictures were like a new traverse across unfamiliar terrain. Progressively revealed was a new planet, detail emerging from obscurity with overwhelming rapidity. ... The new pictures quickly erased from memory the "old" Mars as though the countless hours of previous speculation had been little more than science fiction. (Mutch et al. 1976, 38)

The photos showed that Mars had indeed once been an active planet-with fracture systems, basins, volcanoes, and rifts-but that the dominant processes at work on its surface were not the same as those on the Earth. ${ }^{19}$ Still, this did not prevent geologists from working with terrestrial analogues to explain martian surface features, again incorporating lessons from the field into photogeological evidence. One surface feature, a massive equatorial canyon system, later named Valles Marineris, received quite a bit of comparison with terrestrial canyon systems and rift valleys, leading some to wonder whether Mars showed signs of tectonic activity (Shindell 2004, chapter 4). As NASA geared up for the next step in its Mars exploration program (i.e., the twin Viking landers and orbiters) Science proclaimed that its readers were living in the midst of a revolution in understanding the solar system, and that planetary geology

${ }^{19}$ The previous Mariner flyby missions had returned very moonlike images of the martian surface-barren, cratered, and mostly devoid of interesting morphology. 
was at its heart (Hammond 1974, 720). The discipline of planetary geology was coming into its own in the early 1970 s, and it now seemed to have the support of the general scientific community.

But such progress came with its own anxieties. Even this first generation of planetary geologists, tied as they were to field methods, would admit that the discipline was "in a preliminary descriptive phase" (Mutch et al. 1976, 331). Photogeology had survived Apollo, but if planetary work was to progress-especially in the absence of manned missions or sample returns-its practitioners believed that it needed a way of moving from the observational and descriptive to the hypothetical and deductive. Even the most dedicated terrestrial field geologist, in order to go beyond topography, would take samples into the laboratory for testing, and would use instruments to gather mineralogical data not visible in the field to form and test hypotheses about the geologic processes at work in a site. This analysis of the variety of rock types present in a site was what allowed geologists to make a geological map "a three- or even four-dimensional conceptual model of the underlying geologic structure and history" that incorporated current geological theory and convention with practices performed in the field and laboratory (Cloud 1980, 160). In Lynch's terminology, this was how the geological map, portraying visible, non-visible, and theoretical information, "domesticated" its subject:

In order to put planetary studies on par with terrestrial geology, information analogous to that which was produced in the lab had to be gathered. Much of this was accomplished by the introduction of new remote sensing instruments that could provide more quantitative datasets. In addition to new instruments, the planetary geologists became leaders in the use of remote sensing instruments, and pioneered computer-aided ways of overlaying remotely gathered geophysical and geochemical data on geologic maps of the planets. (Masursky AIP Oral History Interview, June 19, 1987)

Much of this pioneering came from a new generation of planetary geologists, working both within the USGS and externally.

\section{A New Generation of Geologists and Instruments}

During the movement of planetary geology from the Moon to Mars, a new generation of planetary scientists emerged in the universities in the 1970s, at least in part owing to encouraging funding provided by NASA. Universities like Caltech (which managed JPL) reorganized their 
geology departments to incorporate planetary science, and courses in the subject were taught at universities around the country (Tatarewicz 1990; Sharp AIP Oral History Interview, April 26, 1990). ${ }^{20}$ Unlike their predecessors, the geologists trained during this period were not thrown into the new field after standard geological training or military service, but were trained with the datasets, atlases, textbooks, and guides produced by Shoemaker, Mutch, and their colleagues. Moreover, they had been exposed to quantitative methods of geology to a greater degree compared with their predecessors, and did not feel the same need to defend the field from the lab. This generation would participate more so than the first in the production of overlapping remote datasets, a task heavily dependent on the development of new instruments and practices, which ultimately allowed them to make information-rich maps of Mars.

Many in this second generation had their start around the time of the 1976 Viking mission to Mars, which was one of the first to involve students on a large scale. It was also one of the first missions in which the geologists succeeded in collecting global datasets in non-visible wavelengths with orbiting spectrometers. One new instrument introduced on Viking, the Infrared Thermal Mapper (IRTM), was a four-band spectrometer that collected data in the non-visible thermal IR, in wavelengths chosen to correspond to the thermal properties of expected minerals on Mars. ${ }^{21}$ The IRTM was not one of the celebrated life-detecting instruments of the Viking mission, but was onboard to play a supporting role. While the Viking landers were set up to work primarily as remote biological laboratories, their accompanying orbiters were set up to map and study the surface of the planet. This was in part a practical requirement-the orbiters had to determine safe landing sites for the landers before the landers could be released. From the point of view of mission planning, this was one of the main justifications for the IRTM instrument; IRTM was meant to gather information about surface temperatures in candidate sites, which would be used in determining the thermal inertia (a property related to the cooling rate of differently sized geologic materials) of potential landing sites. ${ }^{22}$ Knowing the thermal inertia of a landing site would allow geologists

${ }^{20}$ The transformation of Caltech's Geological Division is described by Robert P. Sharp.

${ }^{21}$ The four bands measured spectra at 6.1 to $8.3,8.3$ to $9.8,9.8$ to 12.5 , and $17.7-24 \mathrm{~m}$ (Kieffer et al. 1976).

${ }^{22}$ Thermal inertia, which is calculated based on the rate of cooling of a planetary surface, can be determined from the difference between the daytime and nighttime surface temperatures. The IRTM experiment used thermal inertia as an indicator of the grain size of the unknown geological material. Denser materials exhibit greater resistance to temperature change. Fine-grained materials like sand, for example, will display greater temperature fluctuation from day to night than will basalt. Knowing the thermal inertia 
to predict whether that site was dangerously rocky or relatively safe (Kieffer et al. 1972). As Viking was billed as a search for martian life and the landers were the stars of the show, it was vital that they not crash in hazardous zones. It was also important to have global information with which to put the lander experiments in context (Kieffer et al. 1972; Jakosky and Christensen 1985).

The IRTM was, along with its Mariner 9 predecessor, the Infrared Interferometer Spectrometer (IRIS), one of the first IR instruments of geologically useful spatial resolution. Unfortunately, insufficient expertise existed on how it should be used from orbit to measure thermal inertia, let alone on how to use it rapidly and in conjunction with images from a visible-light camera to produce meaningful interpretations of surface composition. ${ }^{23}$ Although the instrument did eventually provide overlapping IR datasets for the visible stereoscopic television camera images of the martian surface, the overlapping data could not be collected and analyzed in time to help with selection (Ezell and Ezell 1984). ${ }^{24}$ The IR mappers could not keep up with the established methodology of photogeology, which ended up being the sole influence on landing site selection. ${ }^{25}$

Despite the IRTM experiment team's failure to assist in landing site selection, mission planners and geologists did deem IRTM a successful instrument in the long run. Over the lifetime of the two Viking orbiters, the IRTM provided a global IR dataset for Mars (see Figure 2). Gaining experience with the IRTM in orbit, learning over the course of the mission how to make meaningful representations from IRTM data, the IRTM team was able to make the instrument geologically useful. Developing practices

of a site would thus help to indicate whether it was relatively safe or dangerously rocky. The spatial resolution of the visible-light cameras was not high enough to make these distinctions.

${ }^{23}$ IRIS in fact did have more potential than it was able to realize onboard Mariner 9. Mariner 8, which never reached Mars, was meant to map the planet while Mariner 9 studied temporal changes in the atmosphere and surface of Mars. In order to accomplish the goals of both spacecraft, the remaining Mariner was put into a highly elliptical orbit, which was felt to be the best compromise for the spacecraft's now broadened mission objectives. This less than ideal orbit, along with the IRIS instrument's relatively large field of view, resulted in vastly decreased spectral resolution and thus a reduced chance of detecting compositional emissivity features (Hanel 1999). Because of the nature of the Earth's atmosphere, orbiting spectrometers were not as useful as they potentially were on Mars, and no terrestrial practices involving orbiting spectrometers had developed either.

${ }^{24}$ The problem was exacerbated by the requirement of collecting daytime and nighttime readings from the same area before thermal inertia could be determined.

${ }^{25}$ Deriving thermal inertia for a region of interest required IRTM data from at least two separate passes over the region (ideally one daytime and one nighttime), as thermal inertia is a function of temperature change over time. 


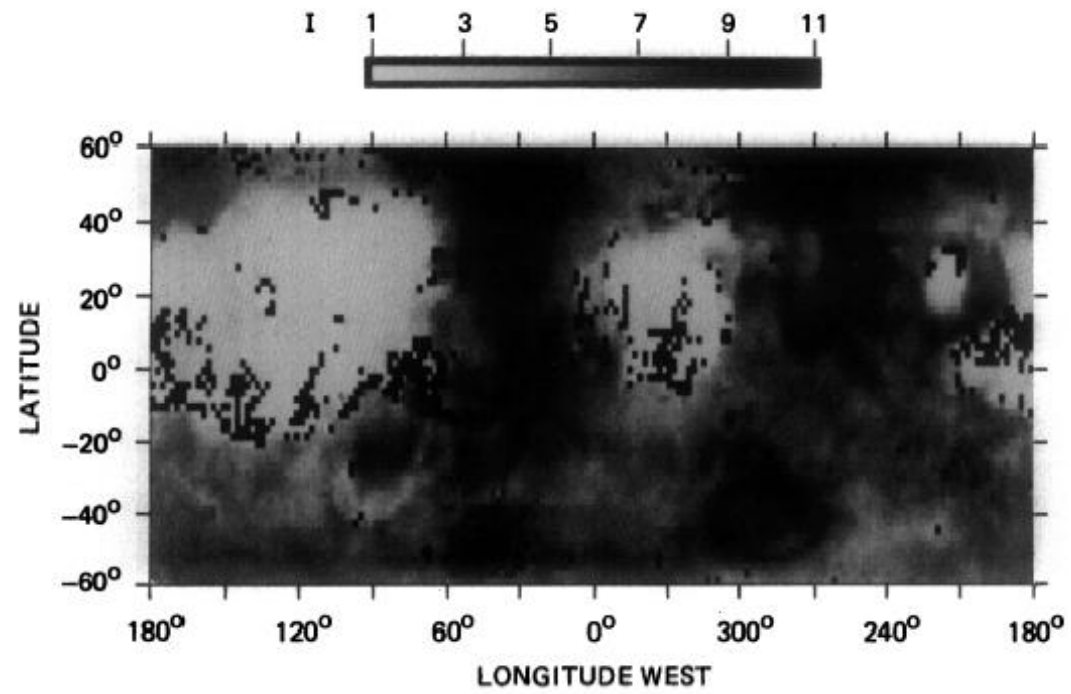

Figure 2. IRTM thermal inertia image of Mars. From Palluconi, Frank D. and Hugh H. Kieffer. 1981. Thermal Inertia Mapping of Mars from 60o S to 60o N. Icarus 45: 415-26. Image reproduced with permission from Elsevier.

that allowed them to use the IRTM in conjunction with the cameras, they were able to create visual representations of martian weather patterns, global dust storms, the redistribution of fine-grained materials on the martian surface, and the seasonal advance and retreat of the frozen polar caps. The IRTM team ultimately did use the collected IR data to make claims about the geologic processes that might have been at work beyond what the visible-light cameras could capture. The instrument's potential in this area convinced NASA that an IR instrument might still be useful for future landing site selection, and the Space Administration remained favourably predisposed toward IR.

\section{The Emergence and Introduction of the Thermal Emission Spectrometer}

Philip R. Christensen trained as a planetary geologist under the guidance of the IRTM experiment's principal investigator, Hugh Kieffer, a USGS geologist and a Professor of Geology at UCLA. ${ }^{26}$ Kieffer advised Christensen, who earned his BS and PhD while working under Kieffer, to pursue an interdisciplinary approach to his geology coursework, which

${ }^{26}$ Kieffer himself represents a transitional figure in this story. He completed his $\mathrm{PhD}$ in geology at Caltech after the Institute had already forged close ties with JPL and the space science community. He did his PhD work under the advisement of Bruce Murray (Kieffer 1968). 


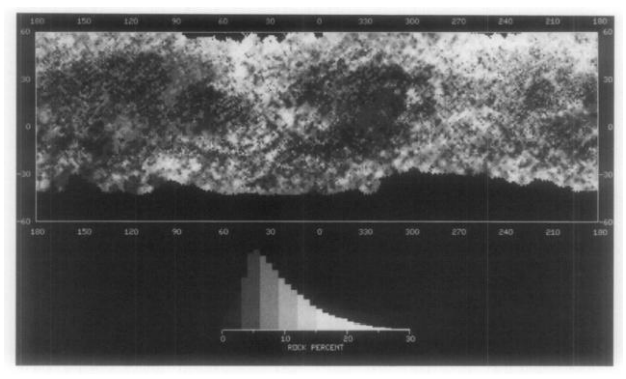

(a)

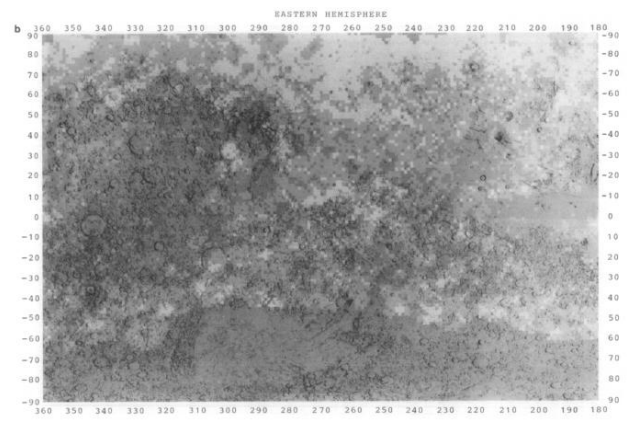

(b)

Figure 3. 3a and 3b. The image at left is Christensen's map of martian rock abundance using IRTM data. The image at right is this same data for the eastern hemisphere of Mars upon a USGS shaded relief map of Mars. From Christensen, Philip R. 1986. The Spatial Distribution of Rocks on Mars. Icarus 68, 217-38. Images reproduced with permission from Elsevier.

integrated physics and geophysics in addition to the courses already required by his department. Christensen also accompanied Kieffer to JPL as an assistant for the Viking missions and participated in the development of methods for the IRTM instrument described above. ${ }^{27}$ In 1981, after the Viking mission had ended, Christensen finished his $\mathrm{PhD}$ dissertation using the IRTM data to calculate and map the global rock abundance on the surface of Mars (Christensen 1981) (see figures 3a and 3b). Although it was produced too late to assist with the Viking landings, this map was later used in the selection of the 1997 Pathfinder landing site, further confirming to NASA the practical value of an improved IR instrument, as well as signifying Christensen's expertise in the use of such an instrument. ${ }^{28}$

Christensen, partly in response to criticism from his peers who said that planetary geology was a primitive and descriptive science, was eager to supplement the existing observational methodologies as much as possible: "We had to get quantitative-what is the composition, what temperature was the lava when it was erupted, how thick is the crust, what was the force required to pull it apart and make those faults" (Christensen 2003). Christensen felt that if he could refine the IRTM, he could get more information than just the relative sizes and abundances of rocks. Some of the differences in the IR energy emitted from the surface were due

${ }^{27}$ This was made possible by a Viking student intern program, initiated by Tim Mutch and Carl Sagan (Masursky AIP Oral History Interview, June 19, 1987).

${ }^{28}$ It is important to note, however, that controversy still existed as to whether or not these maps, or further IR mapping, would help to determine the bedrock geology of the martian surface, or the geologic history of the planet (Golombek 2003). 
to mineralogy, not just size. ${ }^{29}$ Although Christensen had been aware of this fact in constructing his rock abundance map, he had not done much more than consider this a possible source of error in his calculations (Christensen 1986). ${ }^{30}$ Even if the $60 \mathrm{~km}$ spatial resolution of the IRTM had not put constraints on the compositional information that could be extracted from the data, methods for deconvoluting the mixed spectra of materials in situ were as yet undeveloped.

In the process of writing his $\mathrm{PhD}$ dissertation, Christensen began to explore the potential of a thermal IR spectrometer in gathering quantitative mineralogical data from Mars: "As I was thinking about how can you follow up the IRTM, what should be next, it suddenly became obvious that the next thing was to take advantage of all this additional information about the composition of the surface that is present in the infrared. ... But no [geologist] had ever seriously tried to get compositional information from the infrared" (Christensen 2003). As a postdoctoral fellow in Greeley's lab at Arizona State University (ASU), which by that time had developed a small program in planetary geology, Christensen wrote up a development proposal for a new IR instrument. Unlike IRTM, this new instrument would have the spatial resolution necessary to detect the unique emissivity features of different mineral types. He named his new instrument the Thermal Emission Spectrometer (TES), and with Kieffer's blessing contacted the engineers at Raytheon Santa Barbara Remote Sensing who had helped to design and build the IRTM. Christensen and the Raytheon engineers submitted a proposal for TES to NASA's Planetary Instrument Definition and Development Program. ${ }^{31}$ Latching onto mission objectives that Christensen knew NASA valued, the proposal stressed IR's

${ }^{29} \mathrm{IR}$ mineralogy is based on the observation that different minerals should have unique vibrational characteristics due to their molecular composition, and thus emit energy with unique spectral "signatures" or "fingerprints." When Christensen began designing TES, literature on IR mineralogy already existed. Laboratory work on vibrational IR spectra and discussion of its application dated back to the 1950s (Wilson et al. 1955). By the 1970s, geochemists had begun applying vibrational spectroscopy to the study of minerals (Farmer 1974). This work was by and large limited to the laboratory. However, some lunar and simulated lunar work had been explored with near-IR around the time of IRTM (Salisbury et al. 1970; Dybwad et al. 1974). In the early 1980s, Mars was examined telescopically in the near-IR (McCord et al. 1982). During NASA's instrument selection competition, Christensen's TES in fact faced competition from a near-IR instrument proposed by another principal investigator.

${ }^{30}$ These error calculations were also built into the IRTM instrument's spectral range. See note 2, above.

${ }^{31}$ TES combined an infrared $(5.8$ to $50 \mathrm{~m})$ interferometric spectrometer with broadband thermal $(5.1$ to $150 \mathrm{~m})$ and visible/near-IR $(0.3$ to $2.9 \mathrm{~m})$ radiometers (Christensen et al. 2001). 
ability to detect safe and interesting landing sites for robotic missions. It also stressed the types of data that could be constructed using thermal IR datasets, contributing to the global understanding of geologic processes on Mars. Since the Viking landers had failed to detect extant life on Mars, and since the Viking orbiter instrument teams had impressed the public with their ability to do geological work on the planet, NASA had begun emphasizing mission priorities concerning the possibility of past life on Mars, ${ }^{32}$ and had linked this to questions of the planet's geologic history. As such, NASA agreed to fund the instrument's development at Raytheon.

After a competitive instrument selection process, TES was approved and slated to fly on the 1993 Mars Observer spacecraft. Not only did TES offer the opportunity to scout out new landing sites for future landers and rovers, it also promised the kind of dataset that Observer's advocates within NASA hoped to collect. Observer was a fully-loaded spacecraft that signified a new type of mission. It was the first mission of any kind to fly to Mars in the two decades since Viking; in the meantime, planetary geologists of Christensen's generation had continued working with Mariner and Viking datasets to devise testable hypotheses about the geologic history of the martian terrain. The mission would be geared not toward the discovery and description of new surface features, but toward large-scale theory formation and testing via the use of multiple, overlapping, quantitative datasets. ${ }^{33}$ In addition to carrying the high resolution Mars Observer Camera (MOC) and Mars Observer Laser Altimeter (MOLA), Observer also carried an array of instruments that would probe the planet through "much of the electromagnetic spectrum and detect a variety of physical processes" (Albee et al. 1992, 7675). All of this was meant to provide answers to a set of questions raised by the previous Mars missions regarding the geologic history of Mars, namely the role water had played on the planet, the times at which liquid water could have existed on the planet's surface, and where that water had gone. Christensen's TES instrument would participate in constructing this new picture of Mars by seeking out mineralogical evidence related to the past role of water (Albee et al. 1992).

Unfortunately, Observer was lost upon arrival at Mars, three days before its intended entry into orbit (Savage 1993). Faced with the loss of such a heavily loaded and expensive spacecraft, NASA adopted a new policy it described as the "Multi-Year Mars Program," which began

${ }^{32}$ This became the "follow the water" mantra of the NASA Astrobiology Program.

${ }^{33}$ The spacecraft was more capable than past orbiters due to advances in satellite technology since the 1970s. Observer was essentially a converted commercial Earth-orbiting communications satellite loaded with state-of-the-art remote sensing instrumentation. 
in 1996 with the launches of Pathfinder and Mars Global Surveyor (MGS) (McCurdy 2001, 18; NASA 1997). While this program ensured that datasets would be collected more slowly with fewer instruments flying onboard lower-cost spacecraft, and that the new, multilayered picture of Mars would be a longer time coming, it did commit NASA to a continuing program of Mars exploration. After another round of competitive instrument selection, TES was slated to fly onboard MGS. This unexpected turn of events gave Christensen three unscheduled years to perfect TES practices and make it into a geological instrument.

\section{Building a "Center of Calculation" for IR Mineralogy}

Between the loss of Observer and the launch of MGS, Christensen built a Thermal Emission Spectroscopy laboratory and an accompanying facility that became known as the ASU Mars Space Flight Facility. ${ }^{34}$ Christensen, his collaborators, and his students here constructed a research program aimed at making the TES instrument (to use Schaffer's terminology) "transparent" (Schaffer 1989). This work would help Christensen's group to set aside the question of why minerals have certain emissivity features, or why the group had settled upon the thermal IR part of the spectrum as being the most mineralogically useful. Setting these issues aside would allow the group to use the emissivity features of minerals without controversy to identify minerals on Mars. ${ }^{35}$ Once the TES instrument had been switched on and calibrated, the team's discussions of its findings could take place with little or no discussion of the instrument itself-even though the group's authority in these discussions relied upon its special relationship to the instrument. In the lab, the team collected spectra from known rocks and minerals, effectively building a spectral "library" that could act as known controls in computer-aided mathematical comparisons with unknown collected spectra. Working with an interferometric spectrometer in the lab, Christensen's team was able to produce new literature only peripherally related to martian geology, but directly related to a set of claims about the unique spectral properties (or "fingerprints") of different types of rocks. Although many of these rocks contained minerals they

${ }^{34}$ The lab was built around a Nicolet Nexus 670 interferometric spectrometer. ASU dedicated a building to the Facility and encouraged Christensen and others to seek funding from NASA's Astrobiology program.

${ }^{35}$ To make the TES instrument transparent, Christensen and his colleagues could of course draw upon the literature described above in note 29. They also benefited from the long history of the use of infrared spectrometers in physics and chemistry, which had effectively transformed infrared radiation from an object of study into a research tool, and were further aided by the increased use of infrared spectrometers after WWII (Hentschel 2002; Rabkin 2002). 
expected to find on Mars, as time went on they added as many minerals as possible to the library. They also produced quantitative methods of deconvoluting mixed spectral datasets that would aid in extracting mineralogical information from the martian landscape (Christensen and Harrison 1993; Moersch and Christensen 1995; Wenrich and Christensen 1996; Lane and Christensen 1997; Lane and Christensen 1998; Ramsey and Christensen 1998; Feely and Christensen 1999; Christensen et al. 2000). Although the spectrometer in the lab was not the TES instrument, it and the practices surrounding it nonetheless became integral parts of the claims that Christensen and his team would make using TES data.

As TES-collected spectra came back from Mars via MGS, Christensen and the TES science team worked at a pace that had been impossible with IRTM. The spectral library and the methods they devised in their TES lab gave the TES team a unique claim to interpret the TES data, which they used to quantify some of the more interesting differences in the planet's composition. Because the minerals in the library were each connected to geological understandings of how they were formed and what geologic processes they might indicate, the team was able to make arguments about the geologic history of Mars using that data. For example, TES spectra from the surface of Mars could be matched with terrestrial rock spectra indicating that the planet was not just covered in volcanic material, but that this volcanic material was confined basically to two different types of volcanic rock-basalt and andesite. By creating a mineralogical map of the locations of these two types of rock and overlaying it onto photographic data and data from the laser altimeter, Christensen and his team were able to create regional distribution maps of the two types of rock. The distribution of the rocks was shown to be consistent with an already existing dichotomy, based on photogeological evidence and the stratigraphical principle of superposition, between Mars' ancient cratered highlands and its relatively young northern plains. These different minerals, based on terrestrial understandings of their origins, were said to indicate different geological processes at work in the two regions. These maps-the first representations of Mars to provide quantitative mineralogical information-allowed the team to make claims about a geological periodization for Mars (Bandfield et al. 2000; Bandfield 2002; Christensen and Shindell 2003, 16-17).

From their centre of calculation-using the TES instrument's non-visible IR data, combined with the laboratory practices and the spectral library they had created-Christensen and his team reordered and reconstructed Mars in a way that had literally never been seen before. They also successfully enlisted other datasets provided by other instrument teams. Thermal emission spectroscopy data could be overlaid upon altimeter data 


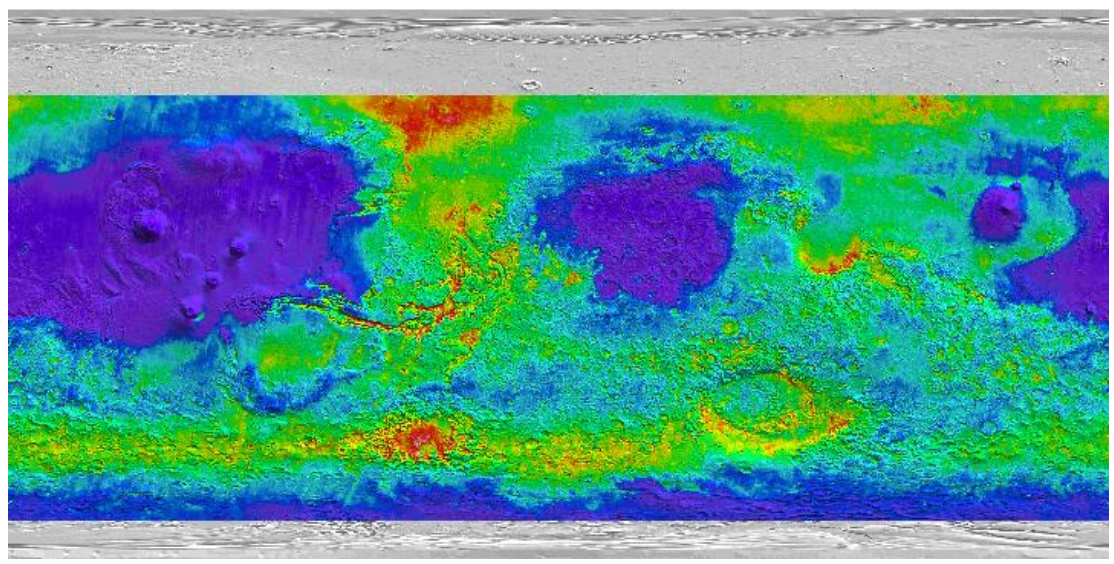

Figure 4. TES thermal inertia dataset, overlaid on top of a MOLA shaded relief map of the martian surface. From Christensen, Philip R. et al. 2001. Mars Global Surveyor Thermal Emission Spectrometer Experiment: Investigation Description and Surface Science Results. Journal of Geophysical Research 106, E10: 23, 823-71. Image courtesy of NASA/JPL/ASU and available at www.mars.asu.edu/data/tes_ti/.

(see Figure 4), or on high-resolution camera images (see Figure 5). Doing this allowed the TES team members and their colleagues to talk about the composition of the rock, as opposed to being limited to descriptions of its appearance and comparisons with terrestrial features. It also imposed constraints upon models and theories that, up until this point, were highly speculative in nature.

Thermal emission spectroscopy also managed to live up to its promise of determining safe and interesting landing sites for future landing or roving missions. In 2002 Bandfield published a TES spectral map of hematite abundance, which showed only one major hematite deposit in a region called Sinus Meridiani. Follow-up work by the TES team confirmed the spectral signature of hematite in the region; this site was eventually selected as the landing site for the MER Opportunity because of hematite's association with water on Earth (see Figure 5). Christensen and his colleagues, using IR data, had now effectively determined landing sites for two separate missions. This track record of success further enforced Christensen's growing authority within the NASA community, which did not go unnoticed when it came time for instrument selection for NASA's 2001 Mars Odyssey and the later MER missions.

\section{From TES to THEMIS}

The phased approach to Mars exploration opened up new opportunities for IR instrument development. In particular, TES was considered valuable because of its ability to map the emissions spectra of the entire 


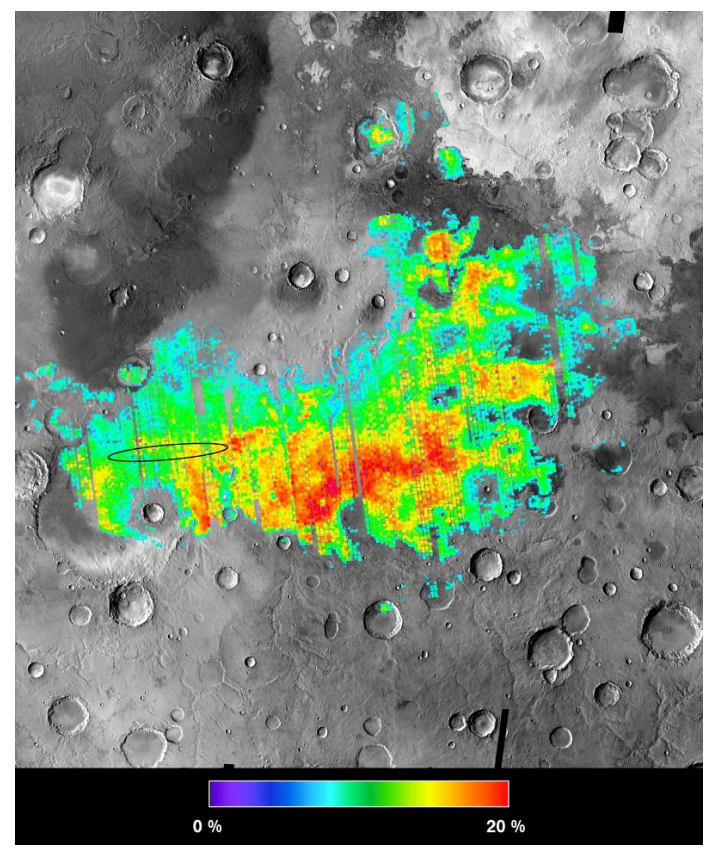

Figure 5. TES evidence of hematite at Meridiani Planum. This evidence influenced NASA's decision to land MER Opportunity within the ellipse shown in the image. Image courtesy of NASA/JPL/ASU and available at themis2.mars.asu.edu/images/meridiani_hematite_orig.

planet at high spectral resolution. Thermal emission spectroscopy had accomplished what Christensen termed "an initial global reconnaissance of mineralogy and thermophysical properties" (Christensen et al. 2004, 87 ), and had effectively stemmed any controversy over the usefulness of thermal IR. ${ }^{36}$ The next IR instrument designed by Christensen's team, the Thermal Emission Mapping Spectrometer (THEMIS), capitalized on TES's discovery of hematite and NASA's growing desire to discover evidence of water on Mars. It also had the built-in ability to produce overlapping datasets on its own. Compared with TES, THEMIS had greater spatial resolution, could be targeted more directly at areas of interest (e.g., possible water-related sites), and could provide high-resolution images to allow the simultaneous gathering of visible and infrared data (see Figure 6). This was meant to "permit mineral and rock distributions to be related to the geologic processes and history of Mars" (Christensen et al. 2004, 86). To that end, THEMIS was designed to look for areas of the martian surface that held mineral deposits associated with hydrothermal or sub-aqueous

${ }^{36}$ Some controversy still remained, however, over whether or not thermal IR was the most useful range of IR wavelengths. Christensen still faced competitors who promoted near-IR as an alternative to thermal IR. 
environments and to select, monitor, and characterize landing sites that might once have hosted such environments. It was also designed to look for thermal evidence of existing hydrothermal systems potentially hiding under the surface of the martian terrain (Christensen et al. 2004).

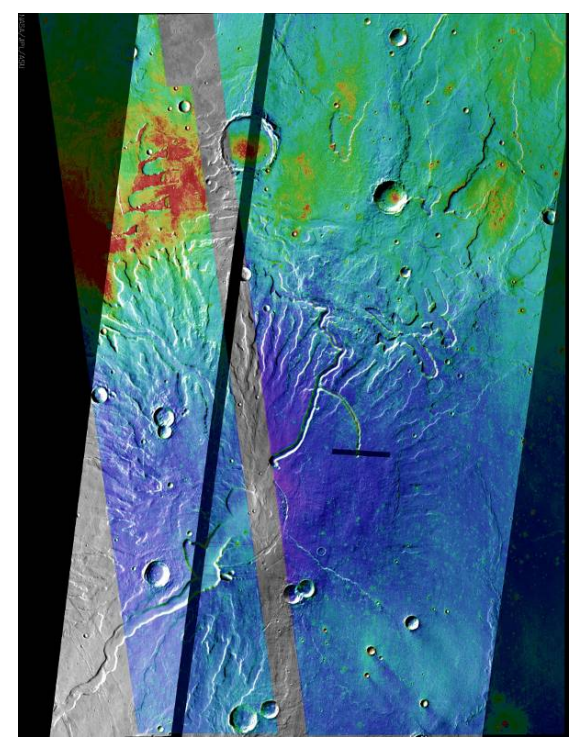

Figure 6. THEMIS image 20041015a is a mosaic of daytime thermal infrared images of Tyrrhena Patera colorized with a mosaic of nighttime temperature images of the site (purple/blue is coldest, yellow/red is warmest). Image courtesy of NASA/JPL/ASU and available at themis.asu.edu/zoom-20041015a . Christensen, P.R., N.S. Gorelick, G.L. Mehall, and K.C. Murray, THEMIS Public Data Releases, Planetary Data System node, Arizona State University, themis-data.asu.edu.

NASA's selection of THEMIS (and later mini-TES) did much to turn Christensen's team's IR conclusions about Mars (at least on a practical level) into incontrovertible claims about the nature of the martian surface. ${ }^{37}$ However, this is not all that was achieved by this succession of instruments. The success of these instruments and their users helped to launch careers in planetary geology. Over the course of the lifetime of TES and THEMIS, Christensen's lab grew. In addition to being a site for IR mineralogy and martian geology, it also became a training facility for graduate students and postdoctoral fellows. From 1994 to 2006, Christensen supervised ten dissertations on infrared geology, most of them dealing directly with the interpretation of martian surface features. During that same period, members of the TES and THEMIS teams

${ }^{37}$ This would seem to be especially true since, although many labs might have access to spectrometers, only one instrument team could claim any kind of ownership to the TES and THEMIS instruments. 
published more than 100 peer-reviewed papers using data from the two instruments. ${ }^{38}$ Not only did this practice produce a new generation of planetary geologists to carry on IR work, it also helped Christensen's ASU Facility to remain competitive with other facilities, such as the nearby University of Arizona, where planetary geologists are trained and new instruments are proposed.

\section{CONCLUSION}

Planetary exploration provided one arena within which field geology could maintain some of its more traditional observational and qualitative methods in the face of a methodological shift in terrestrial geology. External forces played a large role in keeping field work alive. NASA-funded exploration allowed the astrogeologists the shelter of money and institutional walls. The planets afforded them grounds upon which to prove that field methods and the assumptions behind them were neither obsolete nor incommensurable with newer methods. For both Mutch and Wilhelms, for example, planetary geology was a way of not only preserving the "old" methodologies of geology, but of proving their continuing value in exploration. Their interactions with other planetary scientists, although tense, gave them the opportunity to incorporate technologically sophisticated instrumentation, which allowed for both qualitative exploration and the collection of quantitative data sets for hypothesis formation and testing.

Today, thanks to the persistence of its founders and the quantitative contributions of second-generation planetary geologists like Philip Christensen, planetary geology has begun to be incorporated into mainstream geology, or at least has garnered its respect. Looking back on the history of the plate tectonics revolution, plate tectonics insider David Sandwell wrote the following in 2001:

$[T]$ he reason plate tectonics took so long to become an accepted theory is because the earth was explored backward. Detailed geologic structures on the continents were investigated before the entire planet was properly observed, making it difficult to develop a planetary-scale model. The most efficient way to explore a planet is to start with planetary-scale observations and then design small-scale observational programs to test grand hypotheses. Indeed, this

${ }^{38}$ These numbers do not include the researchers and papers produced by participating scientists in the TES and THEMIS experiments. 
is the current NASA strategy for exploring Mars. (Sandwell 2001, 334)

Absent from this statement is any prejudice against either planetary work or observational methods. Sandwell no doubt was influenced by the incorporation of remote techniques by terrestrial geologists in the 1970s, thanks to satellites such as the Landsat series, first put into orbit in 1972.

Although it does not draw explicitly upon the history provided here, NASA's claim that the MER rovers were literally field geologists reflects the disciplinary and instrumental work accomplished by the historical actors described here. That the field geologist has claim to all rocky surfaces was by no means a natural conclusion. As described above, this claim to planetary terrain was successful as a result of Cold War patrons such as the AEC and NASA, the institutional needs of the USGS and the Space Administration, and the ability of the astrogeologists to incorporate remote sensing technologies into a field understanding of geology. Furthermore, although this paper only discussed the origins of one of the instruments onboard the MER-and although not all aspects of this instrument's story can be generalized-it is safe to say that most if not all of the instruments that make up the rovers' "geology toolkit" have an equally rich legacy to the mini-TES instrument, and that each gets its geological pedigree not because of its own special relationship to Mars, but rather because of the geological users and the social practices that surround it. ${ }^{39}$ These users and practices did not form de novo around the rover mission, but rather were cultivated over the course of multiple missions, in universities and research centres, which chose, with NASA's encouragement, to invest and compete in Mars exploration. In short, they make for very interesting sites of analysis.

What might this analysis reveal about the nature of instrumental work in planetary geology and the domestication of the planets? The martian maps discussed in Part 2 were constructed with the aid of a wider array of remote sensing instruments than were the lunar maps of Part 1. These martian maps embody non-visual information connected to instrumental techniques, such as IR mineralogy, and take advantage of computer-aided techniques that allow the non-visible datasets collected by remote instruments to be overlaid on top of photographic or topographic representations of planetary surfaces. The maps discussed in Part 2 rely more heavily upon quantitative, instrumental or laboratory methods than do the maps of Part 1. However, Part 2 demonstrated that these maps are nonetheless just as firmly tied to assumptions about the geologic

${ }^{39}$ Vertesi's examination of the MER mission confirms this view (Vertesi 2009). 
history of the Earth-and the processes through which minerals are formed on the Earth-as were their lunar counterparts. This is not to say that planetary geologists have a terrestrial bias that forces them to recreate the Earth on Mars, but that their domestication of Mars involves resources, both physical and conceptual, that are distinctly terrestrial. By extension, domesticating Mars does not necessarily mean making it more Earth-like; however, it might perhaps be considered second-order domestication, since the externalized retina here involves a familiarity with the already domesticated Earth. If this is the case, then surely the study of the planets cannot be considered anything other than geological.

\author{
MATTHEW SHINDELL \\ Department of History \\ Science Studies Program \\ University of California, San Diego \\ La Jolla, CA \\ mshindel@ucsd.edu
}

\title{
ARCHIVAL SOURCES
}

CITG Caltech Division of Geological and Planetary Sciences Papers, Caltech Archives, California Institute of Technology.

HCU Harold C. Urey Papers, Mandeville Special Collections Library, University of California, San Diego.

HCUN Urey (Correspondence 1959-72), Biographies-Scientists Series, NASA History Archives, NASA History Office, Washington, DC.

\section{INTERVIEWS}

Carr, Michael H. Interviewed by Ronald Doel on June 22, 1987. Niels Bohr Library \& Archives, American Institute of Physics, College Park, MD USA, www.aip.org/history/ohilist/5088.html .

Christensen, Philip R. Interviews by author. Tape and digital audio recordings. Tempe, AZ. May 14, 2002-December 12, 2003.

Greeley, Ronald. Interviews by author. Digital audio recordings. Tempe, AZ. October 9, 2003, April 1, 2004.

Masursky, Harold. Interviewed by Ronald Doel on June 18, 1987, June 19, 1987, and September 8, 1988. Niels Bohr Library \& Archives, American Institute of Physics, College Park, MD USA, www.aip.org/history/ohilist/5081_1.html.

Sharp, Robert P. Interviewed by Ronald Doel on April 26, 1990. Niels Bohr Library \& Archives, American Institute of Physics, College Park, MD USA, www.aip.org/history/ohilist/5086.html.

Shoemaker, Eugene M. Interviewed by Ronald Doel on January 30, 1986, June 16, 1987, June 17, 1987, and September 8, 1988. Niels Bohr 
Library \& Archives, American Institute of Physics, College Park, MD USA, www.aip.org/history/ohilist/5082_1.html.

Wilhelms, Don E. Interviewed by Ronald Doel on June 22, 1987. Niels Bohr Library \& Archives, American Institute of Physics, College Park, MD USA, www.aip.org/history/ohilist/5064.html.

\section{REFERENCES}

Albee, Arden L., Ray E. Arvidson and Frank D. Palluconi. 1992. Mars Observer Mission. Journal of Geophysical Research 97, no. E5: 7665-80.

Bandfield, Joshua L., Vicky E. Hamilton, and Philip R. Christensen. 2000. A Global View of Martian Surface Compositions from MGS-TES. Science 287: 1626-30.

Bandfield, Joshua L. 2002. Global Mineral Distributions on Mars. Journal of Geophysical Research 107: 5042.

Beattie, Donald A. 2001. Taking Science to the Moon: Lunar Experiments and the Apollo Program. New Series in NASA History. Baltimore: Johns Hopkins University Press.

Brush, Stephen G. 1996a. Transmuted Past: The Age of the Earth and the Evolution of the Elements from Lyell to Patterson. New York: Cambridge University Press.

Brush, Stephen G. 1996b. Fruitful Encounters: The Origin of the Solar System and of the Moon from Chamberlin to Apollo. New York: Cambridge University Press.

Chao, Edward C. T., Eugene M. Shoemaker, and Beth M. Madsen. 1960. First Natural Occurrence of Coesite. Science 132: 220-22.

Christensen, Philip R. 1981. The Nature of the Martian Surface as Derived from Thermophysical Properties. PhD dissertation, University of California, Los Angeles.

Christensen, Philip R. 1986. The Spatial Distribution of Rocks on Mars. Icarus 68: 217-38.

Christensen, Philip R., Joshua L. Bandfield, Vicky E. Hamilton, Steve W. Ruff, Hugh H. Kieffer, Timothy N. Titus, Michael C. Malin, Richard V. Morris, Melissa D. Lane, R. L. Clark, Bruce M. Jakosky, M. T. Mellon, J. C. Pearl, B. J. Conrath, M. D. Smith, R. T. Clancy, R. O. Kuzmin, T. Roush, Greg L. Mehall, Noel Gorelick, K. Bender, K. Murray, S. Dason, E. Greene, Steven Silverman, and M. Greenfield. 2001. Mars Global Surveyor Thermal Emission Spectrometer Experiment: Investigation Description and Surface Science Results. Journal of Geophysical Research 106, no. E10: 23823-71.

Christensen, Philip R., and S. T. Harrison. 1993. Thermal Infrared Emission Spectroscopy of Natural Surfaces: Application to Desert Varnish Coatings on Rocks. Journal of Geophysical Research 98, no. 19: 819-34. 
Christensen, P. R., Joshua L. Bandfield, M. D. Smith, Vicky E. Hamilton, D. A. Howard, M. D. Lane, J. L. Piatek, Steve W. Ruff, and W. L. Stefanov. 2000. A Thermal Emission Spectral Library of Rock-Forming Minerals. Journal of Geophysical Research 105: 9735-39.

Christensen, Philip R. and Matthew Shindell. 2003. Mars Infrared. The Planetary Report May/June, 12-17.

Christensen, Philip R., Bruce M. Jakosky, Hugh H. Kieffer, Michael C. Malin, Harry Y. McSween, Kenneth Nealson, Greg L. Mehall, Steven H. Silverman, Steven Ferry, Michael Caplinger and Michael Ravine. 2004. The Thermal Emission Imaging System (THEMIS) for the Mars 2001 Odyssey Mission. Space Science Reviews 110: 85-130.

Christensen, P. R., Steve W. Ruff, R. L. Fergason, Timothy D. Glotch, Noel Gorelick, Bruce M. Jakosky, M. D. Lane, Alfred S. McEwen, Harry Y. McSween, Jr., Greg L. Mehall, K. Milam, J. E. Moersch, Shannon M. Pelkey, A. Deanne Rogers, and W. B. Wyatt. 2005. Mars Exploration Rover Candidate Landing Sites as Viewed by THEMIS. Icarus 187: 12-43.

Cloud, Preston. 1980. The Improbable Bureaucracy: The United States Geological Survey, 1879-1979. Proceedings of the American Philosophical Society 124, no. 3: 155-67.

Cloud, Preston. 1982. The Second Flowering of Geology. Bulletin of the American Academy of Arts and Sciences 36, no. 3: 34-49.

Conway, Erik M. 2008. Atmospheric Science at NASA: A History. Baltimore: Johns Hopkins University Press.

Creager, Angela. 2006. Nuclear Energy in the Service of Biomedicine: The U.S. Atomic Energy Commission's Radioisotope Program, 1946-1950. Journal of the History of Biology 39, no. 4: 649-84.

Dennis, Michael Aaron. 2003. Postscript: Earthly Matters: On the Cold War and the Earth Sciences. Social Studies of Science 33, no. 5: 809-19.

DeVorkin, David H. 1992. Science with a Vengeance: How the Military Created the US Space Sciences after World War II. New York: Springer-Verlag.

Dick, Stephen J. and James E. Strick. 2004. The Living Universe: NASA and the Development of Astrobiology. New Brunswick, NJ: Rutgers University Press.

Doel, Ronald E. 1996. Solar System Astronomy in America: Communities, Patronage, and Interdisciplinary Research, 1920-1960. Cambridge, UK: Cambridge University Press.

Doel, Ronald E. 2003. Constituting the Postwar Earth Sciences: The Military's Influence on the Environmental Sciences in the USA after 1945. Social Studies of Science 33, no. 5: 635-66.

Dybwad, Jens P., Lloyd M. Logan, and Karl B. Zinnow. 1974. Infrared Reflection Spectroscopy of Microscopic Mineral Grains. American Mineralogist 59: 604-07.

Ezell, Edward C. and Linda N. Ezell. 1984. On Mars: Exploration of the Red Planet 1958-1978. Washington, DC: US Government Printing Office. 
Farmer V. C. 1974. Vibrational Spectrometry in Mineral Chemistry. In The Infrared Spectra of Minerals, ed. V. C. Farmer, 1-10. London: Mineralogical Society.

Feely, K. C., and P. R. Christensen. 1999. Quantitative Compositional Analysis Using Thermal Emission Spectroscopy: Application to Igneous and Metamorphic Rocks. Journal of Geophysical Research 104: 24195-210.

Golombek, Matthew P. 2003. The Surface of Mars: Not Just Dust and Rocks. Science 300, no. 5628: 2043-44.

Greene, Mott T. 1985. History of Geology. Osiris, 2nd Series 1: 97-116.

Hammond, Allen L. 1973. 1973: Research Progress on a Broad Front, Earth and Planetary Science, the Copernican Quincentenary. Science 182, no. 4119: 1329-31.

Hanel, R. A. 1999. 1971 Mariner Mars Interferometer Spectrometer (IRIS). Presented at Workshop on Spectroscopy of the Martian Surface: What Next? June 9-10, 1999. Houston, TX: Lunar and Planetary Institute. Available from: www.Ipi.usra.edu/science/kirkland/Workshop1/report.html.

Hentschel, Klaus. 2002. Mapping the Spectrum: Techniques of Visual Representation in Research and Teaching. Oxford: Oxford University Press.

Jakosky, Bruce M. and Philip R. Christensen. 1986. Are the Viking Lander Sites Representative of the Surface of Mars? Icarus 66: 125-133.

Kieffer, Hugh H. 1968. Near Infrared Spectral Reflectance of Simulated Martian Frosts. PhD dissertation, California Institute of Technology, Pasadena.

Kieffer, Hugh H., Gerry Neugebauer, Guido Much, Stillman Chase and Ellis Miner. 1972. Infrared Thermal Mapping Experiment: The Viking Mars Orbiter. Icarus 16: 47-56.

Kieffer, Hugh H., Stillman C. Chase, Ellis D. Miner, Frank Don Palluconi, Guido Munch, Gerry Neugebauer and Terry Z. Martin. 1976. Infrared Thermal Mapping of the Martian Surface and Atmosphere: First Results. Science 193, no. 4255: 780-86.

Kirsch, Scott and Don Mitchell. 1998. Earth-Moving as the "Measure of Man": Edward Teller, Geographical Engineering, and the Matter of Progress. Social Text 54: 100-34.

Lane, M. D. and Philip R. Chirstensen. 1997. Thermal Infrared Emission Spectroscopy of Anhydrous Carbonates. Journal of Geophysical Research 102: 25581-92.

Lane, M. D. and Philip R. Christensen. 1998. Thermal Infrared Emission Spectroscopy of Salt Minerals Predicted for Mars. Icarus 135: 528-36.

Latour, Bruno. 1987. Science in Action: How to Follow Scientists and Engineers through Society. Cambridge, MA: Harvard University Press.

Levy, David H. 2000. Shoemaker by Levy: The Man Who Made an Impact. Princeton, NJ: Princeton University Press.

Lowman, Paul D. 1972. The Geologic Evolution of the Moon. The Journal of Geology 80, no. 2: 125-66.

Lowman, Paul D. 1976. Crustal Evolution in Silicate Planets: Implications for the Origin of Continents. The Journal of Geology 84, no. 1: 1-26. 
Lynch, Michael. 1985. Discipline and the Material Form of Images: An Analysis of Scientific Visibility. Social Studies of Science 15, no. 1: 37-66.

Lynch, Michael. 1988. The Externalized Retina: Selection and Mathematization in the Visual Documentation of Objects in the Life Sciences. Human Studies 11, no. 2-3: 201-34.

McCord, Thomas B., Roger N. Clark and Robert B. Singer. 1982. Mars: Near-Infrared Spectral Reflectance of Surface Regions and Compositional Implications. Journal of Geophysical Research 87: 3021-32.

McCurdy, Howard E. 2001. Faster, Better, Cheaper: Low-Cost Innovation in the U.S. Space Program. Baltimore: Johns Hopkins University Press.

Moersch, J. E., and Philip R. Christensen. 1995. Thermal Emission from Particulate Surfaces: A Comparison of Scattering Models with Measured Spectra. Journal of Geophysical Research 100: 7465-77.

Mutch, Thomas A. 1970. Geology of the Moon: A Stratigraphic View. Princeton, $\mathrm{NJ}$ : Princeton University Press.

Mutch, Thomas A., Raymond E. Arvidson, James W. Head, Kenneth L. Jones and R. Stephen Saunders. 1976. The Geology of Mars. Princeton, NJ: Princeton University Press.

NASA. 1997. Mars Pathfinder Landing: Press Kit. Washington, DC: NASA.

NASA JPL, "NASA Will Send Two Robotic Geologists to Roam on Mars." News release, June 4, 2003. marsrovers.jpl.nasa.gov/newsroom/pressreleases/20030604a.html.

NASA JPL. 2004. Mars Exploration Rover, Mission Fact Sheet.

News Notes. 1960. Science 132, 3436: 1300-04.

Oreskes, Naomi. 1999. The Rejection of Continental Drift: Theory and Method in American Earth Science. New York: Oxford University Press.

Oreskes, Naomi. 2003. A Context of Motivation: US Navy Oceanographic Research and the Discovery of Sea-Floor Hydrothermal Vents. Social Studies of Science 33, no. 5: 697-742.

Palluconi, Frank D. and Hugh H. Kieffer. 1981. Thermal Inertia Mapping of Mars from $600 \mathrm{~S}$ to 60 o N. Icarus 45: 415-26.

Pettijohn, Francis J. 1984. Memoirs of an Unrepentant Field Geologist: A Candid Profile of Some Geologists and Their Science 1921-1981. Chicago: University of Chicago Press.

Rabkin, Yakov M. 2002. Technological Innovation in Science: The Adoption of Infrared Spectroscopy by Chemists. In From Classical to Modern Chemistry: The Instrumental Revolution, ed. Peter J. T. Morris, 3-28. London: Royal Society of Chemistry.

Ramsey, M. S., and Philip R. Christensen. 1998. Mineral Abundance Determination: Quantitative Deconvolution of Thermal Emission Spectra. Journal of Geophysical Research 103: 577-96.

Rankama, Kalervo. 1962. Planetology and Geology. Geological Society of America Bulletin 73: 519-20. 
Rasmussen, Nicolas. 1997. Picture Control: The Electron Microscope and the Transformation of Biology in America, 1940-1960. Stanford: Stanford University Press.

Reinhardt, Carsten. 2006. Shifting and Rearranging: Physical Methods and the Transformation of Modern Chemistry. Sagamore Beach, MA: Science History Publications.

Ronca, Luciano B. 1965. Selenology vs. Geology of the Moon etc. GeoTimes 9, no. 9: 13.

Salisbury, J. W., R. K. Vincent, L. M. Logan, and G. R. Hunt. 1970. Infrared Emissivity of Lunar Surface Features. Journal of Geophysical Research 75: 2671-82.

Sandwell, David T. 2001. Plate Tectonics: A Martian View. In Plate Tectonics: An Insider's History of the Modern Theory of the Earth, ed. N. Oreskes, 331-46. Boulder: Westview Press.

Savage, Donald. 1993. Mars Observer Spacecraft Loses Communications with Earth. Mission Advisory. NASA JPL Public Information Office.

Schaber, Gerald G. 2005. The U.S. Geological Survey, Branch of Astrogeology-A Chronology of Activities from Conception through the End of Project Apollo (1960-1973). U.S. Geological Survey Open-File Report 2005-1190. pubs.usgs.gov/of/2005/1190.

Schaffer, Simon. 1989. "Glass Works: Newton's Prisms and the uses of Experiment." In The Uses of Experiment: Studies in the Natural Sciences, eds. David Gooding, Trevor Pinch and Simon Schaffer, 67-104. Cambridge, UK: Cambridge University Press.

Sheehan, William. 1996. The Planet Mars: A History of Observation and Discovery. Tucson, Arizona: The University of Arizona Press.

Shindell, Matthew. 2004. Outside the Revolution: Turning Points in Planetary Geology and the Introduction of Thermal Infrared Spectroscopy. Master's thesis, Arizona State University.

Shoemaker, Eugene and Robert Hackman. 1962. Stratigraphic Basis for a Lunar Time Scale. In The Moon, ed. Z. Kopal and Z. K. Mikhailov, 289-300. New York: Academic Press.

Tatarewicz, Joseph N. 1986. Federal Funding and Planetary Astronomy, 1950-75: A Case Study. Social Studies of Science 16: 79-103.

Tatarewicz, Joseph N. 1990. Space Technology and Planetary Astronomy. Bloomington: Indiana University Press.

Vertesi, Janet A. "Seeing Like a Rover": Images in Interaction on the Mars Exploration Rover Mission. PhD dissertation, Cornell University.

Wenrich, M. L. and Philip R. Christensen. 1996. Optical Constants of Minerals Derived from Emission Spectroscopy: Application to Quartz. Journal of Geophysical Research 101: 15921-31.

Wilhelms, Don E. 1993. To a Rocky Moon: A Geologist's History of Lunar Exploration. Tucson: University of Arizona Press.

Wilson, E. Bright, Decius, J.C., and Paul C. Cross. 1955. Molecular Vibrations: The Theory of Infrared and Raman Vibrational Spectra. New York: McGraw-Hill. 